\title{
Organics in environmental ices: sources, chemistry, and impacts
}

\author{
V. F. McNeill ${ }^{1}$, A. M. Grannas ${ }^{2}$, J. P. D. Abbatt ${ }^{3}$, M. Ammann ${ }^{4}$, P. Ariya ${ }^{5}$, T. Bartels-Rausch ${ }^{4}$, F. Domine ${ }^{6}$,

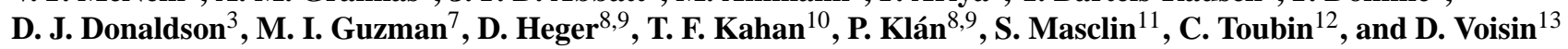 \\ ${ }^{1}$ Department of Chemical Engineering, Columbia University, New York, NY 10027, USA \\ ${ }^{2}$ Department of Chemistry, Villanova University, Villanova, PA 19085, USA \\ ${ }^{3}$ Department of Chemistry, University of Toronto, Toronto, ON, M5S 3H6, Canada \\ ${ }^{4}$ Laboratory of Radio- and Environmental Chemistry, Paul Scherrer Institute, 5232 Villigen, Switzerland \\ ${ }^{5}$ Department of Chemistry and Department of Atmospheric and Oceanic Sciences, McGill University, Montreal, PQ, \\ H3A 2K6, Canada \\ ${ }^{6}$ Takuvik International Laboratory, Université Laval and CNRS, Québec, QC, G1V 0A6, Canada \\ ${ }^{7}$ Department of Chemistry, University of Kentucky, Lexington, KY 40506, USA \\ ${ }^{8}$ Department of Chemistry, Faculty of Science, Masaryk University, Kamenice 5, 62500 Brno, Czech Republic \\ ${ }^{9}$ Research Centre for Toxic Compounds in the Environment, Faculty of Science, Masaryk University, Kamenice 3, 62500 \\ Brno, Czech Republic \\ ${ }^{10}$ Department of Chemistry, Syracuse University, Syracuse, NY, 12344, USA \\ ${ }^{11}$ Environmental Systems, University of California, Merced, Merced, CA 95343 USA \\ ${ }^{12}$ Laboratoire PhLAM - UFR de Physique, Université Lille, 59655 Villeneuve D’Ascq Cedex, France \\ ${ }^{13}$ LGGE/OSUG, Université Joseph Fourier, 38402 Saint Martin d'Hères, France
}

Correspondence to: V. F. McNeill (vfm2103@columbia.edu)

Received: 25 March 2012 - Published in Atmos. Chem. Phys. Discuss.: 10 April 2012

Revised: 12 September 2012 - Accepted: 12 October 2012 - Published: 24 October 2012

\begin{abstract}
The physical, chemical, and biological processes involving organics in ice in the environment impact a number of atmospheric and biogeochemical cycles. Organic material in snow or ice may be biological in origin, deposited from aerosols or atmospheric gases, or formed chemically in situ. In this manuscript, we review the current state of knowledge regarding the sources, properties, and chemistry of organic materials in environmental ices. Several outstanding questions remain to be resolved and fundamental data gathered before an accurate model of transformations and transport of organic species in the cryosphere will be possible. For example, more information is needed regarding the quantitative impacts of chemical and biological processes, ice morphology, and snow formation on the fate of organic material in cold regions. Interdisciplinary work at the interfaces of chemistry, physics and biology is needed in order to fully characterize the nature and evolution of organics in the cryosphere and predict the effects of climate change on the Earth's carbon cycle.
\end{abstract}

\section{Introduction}

From cirrus ice particles in the atmosphere to sea ice and snow on the Earth's surface, ice is a key component of the biogeochemical cycle of carbon. The cryosphere is one of the most poorly understood components of the Earth system, yet one of the most vulnerable to climate change.

The interaction of organic materials with environmental ices plays an important role in a number of biogeochemical and climate processes (Fig. 1). Organic materials present in snow and ice are often light-absorbing species, akin to "brown carbon" in atmospheric aerosols. This absorbing material contributes up to $40 \%$ of the integrated absorbance between 300-750 nm (Doherty et al., 2010; Hegg et al., 2010). This contribution adds to the absorbance of black carbon (BC), the main absorber in snow, which is calculated for observed concentrations to reduce the albedo by $2-5 \%$ on Himalayan glaciers (Yasunari et al., 2010). Such a reduction of albedo contributes to the so-called snow-albedo feedback mechanism, significantly amplifying climate change in 


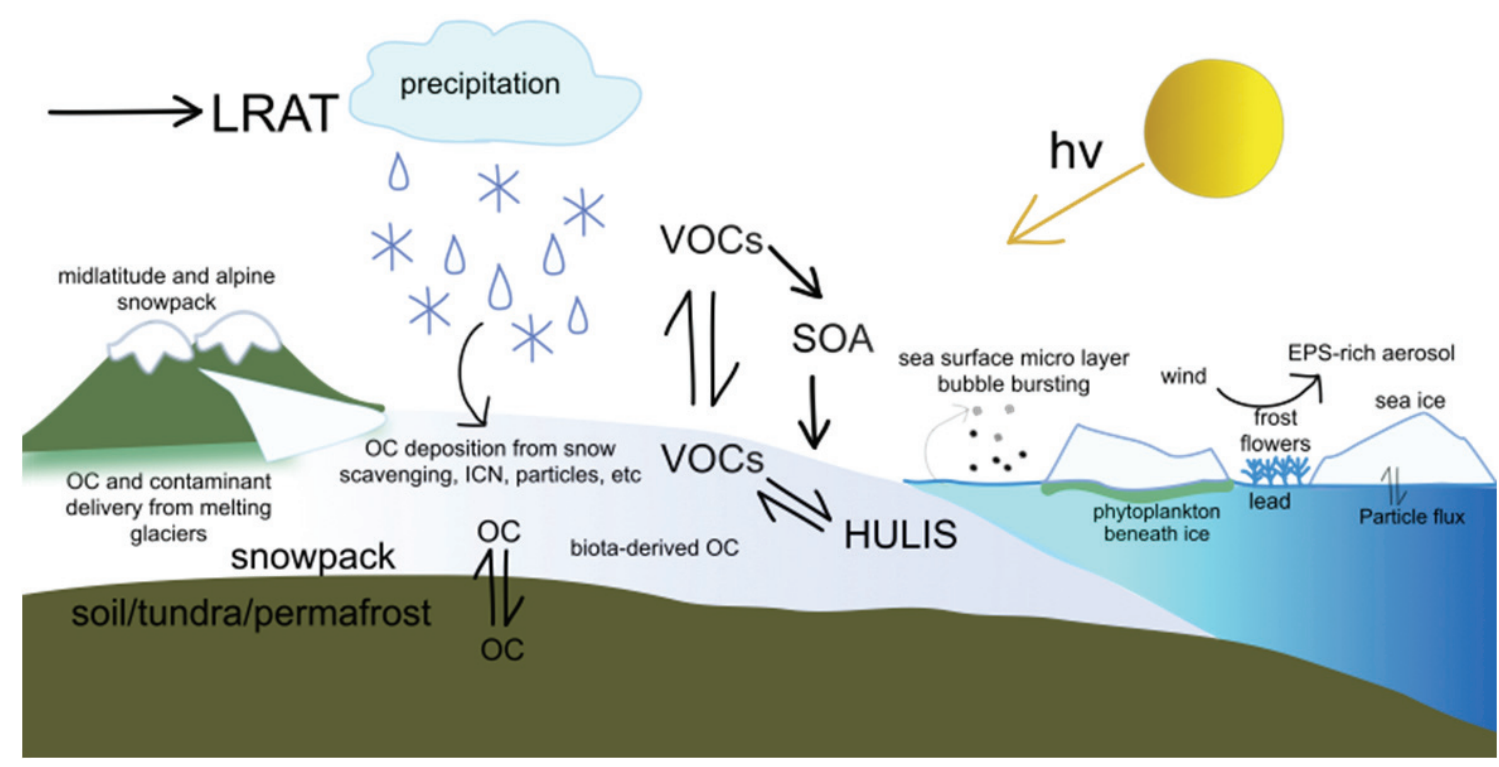

Fig. 1. Biogeochemical cycle of organic carbon in the cryosphere. LRAT: long range atmospheric transport. VOC: volatile organic compound. SOA: secondary organic aerosol. HULIS: humic-like substances. EPS: exopolymeric substances.

the Arctic (Flanner et al., 2007; McConnell et al., 2007). Feedbacks between organics in the cryosphere and atmospheric aerosols impact the aerosol direct and indirect effects on climate and the hydrological cycle (Lohmann and Leck, 2005). For example, microbial exopolymeric secretions can be directly incorporated into marine aerosol by wind blowing across frost flowers (Shaw et al., 2010). These aerosols can be directly incorporated into growing snow crystals (Domine et al., 2011). Deposition of these atmospheric aerosols and of the snow that contains them is thought to be a significant source of organics in snow (Hegg et al., 2010).

Both abiotic and biotic processes play a role in the cycling of carbon in environmental ices. Organic carbon in snow and sea ice may have its origins in plant material, microorganisms and their excretions, or aerosols or volatile organic compounds (VOCs) deposited from the atmosphere (Xu et al., 2010; Pautler et al., 2011). Organic impurities in snow can originate during snow formation and snowfall or after the snow has been deposited on the ground. They can originate from atmospheric aerosol particles acting as a condensation nucleus, be incorporated during crystal growth (either as gases or particles), or scavenged during precipitation (also either as gases or particles (Lei and Wania, 2004)). They can also be deposited onto snow on the ground or filtered by the snow from air flowing through the snowpack by wind pumping (Albert and Shultz, 2002). It has been discussed previously that photochemistry of organic compounds changes the composition of the snowpack/ice impurities (Klan and Holoubek, 2002) and leads to VOC production (Grannas et al., 2007b). Helmig et al. (2009) showed that the snowpack can act as a source for some gas phase species $\left(\mathrm{CO}_{2}, \mathrm{CHCl}_{3}\right.$, $\left.\left(\mathrm{CH}_{3}\right)_{2} \mathrm{~S}, \mathrm{CS}_{2}, \mathrm{CHBrCl}_{2}\right)$ or as a sink for others $(\mathrm{CO}, \mathrm{COS}$, some halogenated compounds and hydrocarbons). Biological activity in snow and sea ice is another important but asyet poorly constrained source of VOCs (Ariya et al., 2011). Environmental ices provide a medium and nutrients for bacterial and fungal growth and associated physicochemical processes (Domine et al., 2002). VOCs impact the surrounding environment in a number of ways: they control the oxidizing capacity of the atmosphere (Perrier et al., 2002), contribute to the formation of secondary organic aerosol (Seinfeld and Pankow, 2003; Ervens and Volkamer, 2010) and can produce humic-like substances in snow and ice (Guzman et al., 2007).

This is the first review to comprehensively present the chemical and physical issues that arise at the molecular level when organic species become associated with snow and ice. We discuss the current state of knowledge regarding the presence of organic materials in environmental ices, their sources, chemistry, and local, regional and global impacts on the cryospheric organic carbon cycle. We begin with a discussion of field observations in Sect. 2. Section 3 reviews the mechanisms of organics incorporation and cycling in environmental ices. Physical, chemical and biological processes that impact organic carbon are considered in turn. In Sect. 4, the impact of environmental ices on the local, regional and global carbon cycle is discussed. In particular, we point out that because the impacts of ice-organic interactions on the carbon cycle is an emerging area, it is difficult to make firm conclusions from the work done in this area to date. Finally, in Sect. 5 we provide a future outlook for the scientific community, discussing aspects of the various processes that are not well understood and suggest potential areas of focus for future research endeavors. 


\section{Synthesis of field observations to date}

A wide variety of organic compounds have been discovered in snow. Their sources may be chemical, physical (e.g., deposition), or biological. Here we discuss results from field measurements of organic material in snow and other environmental ices in polar, sub-polar and temperate regions. We focus on measurements made since the 2007 review of Grannas et al., which provided a general overview of important topics in snow photochemistry, including some material on organics in snow and ice.

Recent measurements of organic compounds at high altitude or high latitude sites point to the potential impact of topography and air mass transport on the organic content of snow. The deposition of organic compounds in the Himalayas has been found to be a seasonally dependent function of air mass transport from China and Central Asia, as evidenced in measurements of 16 polycyclic aromatic hydrocarbons (PAH) over glaciers of the Tibetan Plateau ( $\mathrm{Li}$ et al., 2011) and detection of specific persistent organic pollutants (POP), e.g., organochlorine pesticides and polychlorinated biphenyls, in the snow of a Himalayan glacier (Kang et al., 2009).

Usenko et al. (2010) observed similar impacts of topography on the atmospheric transport and deposition of PAHs in high elevation sites of some Western US National Parks. While phenanthrene (Phe), fluoranthene (Fla) and pyrene (Pyr) were the major PAHs to be detected on these sites, Gabrieli et al. (2010) used the ratio Fla/(Fla+Pyr) for source assignment. Its value in high-altitude alpine snow and ice shows an increase in the contribution of diesel and gasoline combustion with respect to coal and wood combustion from 1860 to 1980; a trend that reversed over the past two decades.

Measuring POPs in one glacial and one non-glacial-fed stream in the Italian Alps, Bizzotto et al. (2009) suggested that changes in PCB concentration may be caused by local emissions rather than long-range transport. They also investigated the role of the snowpack as an organic reservoir by comparing the levels of POPs in the two streams during the snowmelt season, as Meyer et al. (2011b) did with a similar study based on PAHs. Through measurement of benzene, alkylated benzenes, chlorinated hydrocarbons and monoterpenes, Fries et al. (2008) pointed to the potential of snow/ice to be an efficient scavenger of atmospheric VOCs. This potential depends essentially on meteorological parameters (temperature, wind speed and direction, humidity, cloud cover and precipitation) and on source strengths. Semivolatile organics, such as naphthalene, will be released into the atmosphere from melting snowpack due to evaporation (Meyer et al., 2011a).
Although the source plays a role in the characteristics of organic matter observed in snowpack, post-depositional processing also plays a role in the nature of organics found in snow and ice. A number of laboratory and field studies have investigated the photochemical behavior of anthropogenic contaminants in snow and ice. These studies are discussed in Sect. 3.2.2. We also note that the review of Grannas et al. (2012) in this special issue covers the topic of persistent organic pollutants in the cryosphere in more detail.

Measurements of water-soluble organic carbon (WSOC) at Summit, Greenland (Anderson et al., 2008; Hagler et al., 2007) and of dissolved organic carbon (DOC) at Barrow, Alaska (Voisin et al., 2012) show evidence of postdepositional processes that contribute to substantial loss of organic carbon in the top surface snowpack. These studies suggest that snowpack is a source of organic carbon to the atmosphere through possible outgassing and/or photochemical processes von Schneidemesser et al. (2008) attributed the absence of a seasonal pattern in organic compounds in Greenland snow (hopanes, PAHs, alkanes, alkanoic acids) to possible post-depositional processing occurring in the snowpack. Other studies also point to the fact that concentrations of gas phase formaldehyde (HCHO) measured in the Arctic (Mabilia et al., 2007) and in Antarctica (Salmon et al., 2008) cannot be explained by known gas-phase chemistry without considering an additional source of $\mathrm{HCHO}$ from the snowpack, in support of previous observations (Sumner et al., 2002; Sumner and Shepson, 1999). In further support of these observations, Barret et al. (2011a) showed that the seasonal snowpack near Barrow, Alaska, was a source of HCHO and that, while most of the $\mathrm{HCHO}$ produced was released to the atmosphere, a small fraction was incorporated into surface snow crystals by solid state diffusion. Yet, such postdepositional processing is not always important: measurements of higher dicarboxylic acids (C5-C13) in alpine snow (Winterhalter et al., 2009) revealed these species are not affected by post-depositional processes. This could be related to the higher accumulation rates observed in the Alps; carbon deposited to the snow spends less time in the photic zone of the snowpack, as proposed by Preunkert et al. (2003) for nitrate.

A detailed evaluation of the species and mechanisms responsible for the observed carbon reemission to the atmosphere is difficult because of the very high number of organic species present in the snow (Grannas et al., 2006), of which only a fraction is thoroughly quantified and investigated. Organic carbon was recently speciated in an alpine ice core (Legrand et al., 2007) spanning the last $50 \mathrm{yr}$ of snow accumulation, and in Arctic Alaska coastal snow (Voisin et al., 2012). Up to $40 \%$ of DOC was identified as formaldehyde and short chain mono and diacids in the alpine ice core, whereas in the Alaskan snow, only up to $20 \%$ was identified as short chain aldehydes and diacids, as well as humic-like substances (HULIS). 
Another source of uncertainties specific to photochemical processes in snowpacks is related to radiative transfer in the snow. Warren and Wiscombe (1980) clearly showed that absorbing impurities such as $\mathrm{BC}$ have a large effect on snow optical properties. Based on these calculations, recent model estimates (Flanner et al., 2007; Yasunari et al., 2010) show a large influence of such impurities on snow albedo, and thus on climate. This prompted studies on light absorbing aerosols in snow (Hegg et al., 2009; Doherty et al., 2010; Hegg et al., 2010). Spanning the entire Arctic, these studies show that besides $\mathrm{BC}$, there is a clear contribution from Brown Carbon $(\mathrm{BrC})$ to the absorbance of insoluble material in the snow. This mixture of black and brown carbon was mainly attributed to biomass burning of two kinds: boreal wood burning and crop and grass burning. The contribution of $\mathrm{BrC}$ to the total absorbance of the filters compares to $\mathrm{BC}$ absorbance in the UV part of the solar spectrum, making $\mathrm{BrC}$ an important parameter in evaluating UV penetration and photodissociation constants in the snowpack. Insoluble $\mathrm{BrC}$ is estimated around $10 \mathrm{ppbC}$ in North America, and up to $50 \mathrm{ppbC}$ on average in Siberia. These concentrations are in the same range as $\mathrm{BC}$ concentrations, from 5 to $30 \mathrm{ppb}$ on average (also higher in Siberia). Some absorbance in the snow is related to soluble species. Anastasio and Robles (2007) measured the absorbance of melted filtered snow, and evaluated the contributions of nitrate and $\mathrm{H}_{2} \mathrm{O}_{2}$ to this absorbance. They found that in Summit, Greenland and Dome C, Antarctica, half of the absorbance was due to unknown, probably organic chromophores. The same experiment was recently repeated in terrestrial snow and in marine ices (snow, frost flowers and sea ice) in Barrow, Alaska (Beine et al., 2011, 2012): nitrate and $\mathrm{H}_{2} \mathrm{O}_{2}$ only represented a few percent of the total absorbance on land and less than $1 \%$ on marine samples. The highest contributor was HULIS, although they only represent $10 \%$ of DOC in land samples (Voisin et al., 2012). The remaining unknown chromophores represent half of the total absorbance and are seemingly related to a marine source.

These measurements (filter absorbance for the insoluble fraction; absorbance of melted filtered snow for the soluble fraction) are potentially biased because $\mathrm{BC}$ and $\mathrm{BrC}$ do not necessarily have the same optical properties on a filter and in the snow, or solvated in water and in the snow. For example, glyoxal, which is the second most concentrated aldehyde in the snow in Barrow (Barret et al., 2011a) absorbs efficiently in the UV in its aldehyde form, but does not absorb once hydrated in liquid water, where it exists as a diol.

Direct measurements of actinic fluxes in the snowpack were initially used to estimate photolysis constants for use in snowpack chemistry modeling (e.g., Lee-Taylor and Madronich, 2002; Fisher et al., 2005). Measurements of light penetration into the snow, snowpack reflectance and density were recently associated to a coupled snow- atmosphere radiative-transfer model TUV-snow (Lee-Taylor and Madronich, 2002) to obtain information on absorbers' iden- tity and concentrations in Dome C, Antarctica (France et al., 2011) and in Barrow, Alaska (France et al., 2012). Fitting the observed absorption coefficient is only possible with a Brown Carbon type absorber in addition to Black Carbon. In Barrow, $\mathrm{BC}$ concentrations estimated from these optical properties are 10 times higher than chemical BC measurements (Doherty et al., 2010, Voisin et al., 2012). This discrepancy could be due in part to problems in evaluating the absorption coefficient for $\mathrm{BC}$ (and maybe $\mathrm{BrC}$ ) in snow as a function of BC location in the ice lattice (Flanner et al., 2012), but most likely arises from the the difficulty in making quantitative comparisons between these very different analytical methods.

In polar coastal and temperate areas, microbial interactions in snow and ice will also affect the organic matter present. Pointing at the potential role of dissolved organic carbon (DOC) in organic cycling on Arctic shelves, Riedel et al. (2008) suggest that seasonal cycles of algae control the budget of particulate organic carbon and exopolymeric substances in first-year sea ice and their release to the atmosphere. This hypothesis is supported by Norman et al. (2011) who observed that sea ice melt may both affect the spectral characteristics of colored dissolved organic matter (CDOM) and act as a source of fresh autochthonous (marine) CDOM and labile DOC. Bhatia et al. (2010) also found that autochthonous microbial processes on the ice sheet produce the majority of supraglacial dissolved organic matter (DOM), whereas allochthonous (terrestrial) carbon from overridden soil and vegetation plus carbon from in situ microbial activities constitute subglacial DOM, with a seasonally dependent contribution. This conclusion was only reached though advances in analytical methods, e.g. electrospray ionization (ESI) Fourier transform ion cyclotron resonance (FT-ICR) mass spectrometry coupled to multivariate statistics, reaching unprecedented molecular level characterization of the organic material present.

All these biochemical transformations that may occur in ice and snow heavily modify the properties of organic matter. It was recently shown that organic matter produced in snow and ice was more labile than DOC regularly found in rivers (Holmes et al., 2008; Hood et al., 2009). As DOC in Arctic watersheds comes primarily from snowmelt (Finlay et al., 2006), this processing of organic matter by snow and ice processes may impact our understanding of the carbon biogeochemical cycle at high latitudes.

Important efforts have focused on the improvement and development of new or well-known analytical methods to detect lower concentrations of chemical species and to help monitor concentrations and fluxes of organic compounds over study sites. Lacorte et al. (2009) optimized the ultratrace detection of 48 POPs in ice using stir bar sorptive extraction (SBSE) gas chromatography coupled to mass spectrometry (GC-MS). In addition to its use as an in situ analytical method, this optimization leads to limits of detection down to the $\mathrm{pg} \mathrm{L}^{-1}$ level, so many of the POPs in ice can 
be quantified using far smaller sample sizes than previously necessary. Detection of higher dicarboxylic acids has also been improved with the optimization of solid-phase microextraction (SPME), followed by analysis using HPLC coupled to a hybrid mass spectrometer (HPLC-MS-TOF) (Kippenberger et al., 2008; Winterhalter et al., 2009). In 2010, Kos and Ariya (2010) improved the GS-MS detection of VOCs in snow after SPME, using a splitless injection which increased considerably the sensitivity and decreased limits of detection (LOD ranged from $0.3 \mathrm{ng} \mathrm{L}^{-1}$ for benzene to $36 \mathrm{ng} \mathrm{L}^{-1}$ for 1,2-dichlorobenzene). For qualitative and quantitative analysis of BTEX (benzene, toluene, ethylbenzene, o-, mand p-xylene) and n-aldehydes (C6-C10) in melted snow water, Sieg et al. (2008) optimized several extraction and desorption parameters for the development of an analytical method based on headspace-solid-phase dynamic extraction (HS-SPDE) followed by GC-MS. With a LOD range from $19 \mathrm{ng} \mathrm{L}^{-1}$ (benzene) to $63 \mathrm{ng} \mathrm{L}^{-1}$ (n-hexanal), the authors detected BTEX and aldehydes in alpine snow. Ultra-trace levels of semi-volatile and non-volatile organic compounds from snow melt water samples were quantified with the development of a dichloromethane liquid-liquid extraction plus GC-MS analytical method (von Schneidemesser et al., 2008). However, this technique is not yet optimized for the detection of very polar or non-polar compounds as many species still remain below the limit of detection.

\section{Mechanistic insight from field, laboratory, and modeling studies}

Ice in the environment may exist in the form of ice or snow at the Earth's surface or frozen cloud particles in the troposphere or stratosphere. Impurities in snow can be molecules or ions adsorbed to or dissolved in crystals, aerosol particles which originated as a condensation nucleus (Parungo and Pueschel, 1973), gases and particles scavenged during precipitation (Lei and Wania, 2004), or species deposited onto snow on the ground (Domine et al., 2004). The amount and location of chemical species incorporated into growing ice crystals depends on the snow formation mechanism, i.e., whether the crystal forms by freezing supercooled water or by water vapor condensation. Once deposited on the surface, snow is a porous medium that continues to undergo morphological changes due to changes in ambient temperature and radiative heating (Domine et al., 2008). The void space of the snowpack consists of air which undergoes exchange with the ambient atmosphere and contains trace species which interact with the ice crystals (Domine and Shepson, 2002). Environmental ice and snow represent thus a complex matrix where physical exchanges, chemical reactivity and biological processes can occur in distinct, different local environments. The physical and chemical properties of these local environments (compartments) directly influence the overall reactivity, and vice versa. This has been reviewed in detail in a companion paper in this Special Issue (Bartels-Rausch et al. (2012)). In brief, and as evident from the history of snow described above, surface snow, sea-ice, and ice clouds may provide a variety of environments for interaction with and reaction of organics, including: neat ice surfaces, grain boundaries, a neat ice crystal matrix, liquid phase, and waterinsoluble solids.

A nanoscale region of surface disorder exists on pure ice near the melting temperature, often referred to as a quasiliquid layer (QLL). The QLL on pure ice is not a phase predicted by equilibrium thermodynamics. It is an interfacial medium thin enough that most molecules are affected by the nearest interface. Therefore, properties of molecules in a QLL are different from those in a liquid. For this reason, we recommend the use of the term disordered interface (DI). Affected properties include mobility, interaction with other molecules, and possibly reactivity. A key question is how chemical and physical processes on ice are influenced by the DI, and vice versa (Bartels-Rausch et al., 2012). Grain boundaries containing relatively low impurity concentrations may share some of the characteristics of the DI, but little is known about this.

When sufficient solute is present, the chemical potential of the interfacial layer increases sufficiently for an extra phase to form, as predicted by equilibrium thermodynamics. Down to a few tens of degrees below $0{ }^{\circ} \mathrm{C}$, this phase can exist in equilibrium with the ice and the gas phase, and is often called a brine (Cho et al., 2002; Kuo et al., 2011). The brine may exist at the gas-ice interface where it is available for reactions on short time scales, or be segregated inside the ice sample from where its solutes can only escape on long timescales (i.e., in grain boundaries, triple junctions, or inclusions within crystals). The presence of a brine changes the reactivity of environmental ices changes drastically. For more details on the influence of ice microphysics on air-ice chemical interactions please see Bartels-Rausch et al. (2012).

Physical, chemical, and biological processes can affect the properties and cycling of organic materials in environmental ices. In the following sections we present an overview of these processes from field, laboratory and modeling perspectives.

\subsection{Physical sources and sinks}

Quantifying the physical interaction of trace gases with ice and snow is critical to predicting the influence of environmental ices on atmospheric composition. Key physical processes include sorption onto the surface (with or without DI), dissolution into a liquid phase, and solid-state dissolution and diffusion. While surface-gas interactions are well-understood for many other substrates (Adamson, 1990), the dynamic nature of the ice surface has made this a challenging task. Ice is a comparatively high vapor-pressure solid (Murphy and Koop, 2005), which makes experimental characterization of the ice surface challenging, particularly at temperatures near 
the melting point. Adsorbates can be buried by incoming water molecules (Gertner and Hynes, 1998; Ullerstam and Abbatt, 2005) and, even below $210 \mathrm{~K}$, the surface layer is refreshed on a timescale of 0.1-0.001 s (Haynes et al., 1992). Nevertheless, this exchange remains slow as compared to the molecular motion of the water molecules in the hydrogen bond structure (Girardet and Toubin, 2001). The state of the ice surface also varies as a function of temperature. The extent of the DI increases with increasing temperature, and may be affected by solutes (Wettlaufer, 1999).

\subsubsection{Adsorption and desorption}

In the following section we discuss the adsorption and desorption of organic species to and from snow and ice surfaces, and how these processes influence the transport of organic trace gases through snowpack.

\section{Molecular-level picture}

The adsorptive uptake of trace gases to ice has been reviewed previously by Girardet and Toubin (2001), Abbatt (2003), Huthwelker et al. (2006), and Bartels-Rausch et al. (2012), and summarized in the IUPAC evaluation (Crowley et al., 2010). Although a majority of the laboratory studies of airice chemical interactions in the literature focus on this topic, significant uncertainty still exists at the molecular level regarding the identity of the adsorption site, the state of the adsorbate on the surface, and the nature of the adsorbatesubstrate interactions. Molecular dynamics (MD) simulations have been used in connection with experiments in order to characterize the adsorption and the binding properties of organic species at the ice/air interface and elucidate the molecular processes important for the atmospheric chemistry.

Adsorption of impinging gas phase molecules by the ice surface tends to be favorable, due in part to the highly dynamic character of the hydrogen bond structure. Accommodation on the surface is therefore in general not a rate limiting step, especially not on the time scales relevant for snow chemistry. Therefore, within the present context, equilibrium partitioning between the gas and the surface with its temperature dependent energetics has usually been investigated.

In laboratory studies, which have for the most part used loss of a species from the gas phase as an observable, adsorption has generally been found to be reversible and welldescribed by a nondissociative Langmuir model (Abbatt, 2003). These studies are generally conducted at temperatures of $245 \mathrm{~K}$ or lower due to experimental difficulties in working with ice close to the melting temperature. Starr et al. (2011) present direct spectroscopic evidence of adsorbed acetone at the ice surface and reasonable fits of surface coverage isotherms by the Langmuir model. They derive an adsorption configuration with one strong hydrogen bond be- tween the carbonyl oxygen and the dangling $\mathrm{OH}$, and one or two weak hydrogen bonds between the methyl hydrogens and the substrate oxygens from comparison of experimental with calculated X-ray absorption spectra. Bartels-Rausch et al. (2004) found that the thermodynamics of acetone uptake did not vary across four types of laboratory ice and snow samples with varying crystal grain size and surface areas. This suggests that adsorption takes place on the crystal face rather than in grain boundaries for this and probably other oxygenated organic species. While Behr et al. (2006) found more complex behavior at $190 \mathrm{~K}<T<220 \mathrm{~K}$, this was probably more due to structural transformations of the vapor-deposited ice samples. Metastable-impact-electron spectroscopy (MIES) experiments and classical MD simulations showed that $\mathrm{MeOH}$ adsorbs with the hydroxyl group pointing toward dangling bonds of the ice surface, forming two hydrogen bonds with the surface (H-donor and $\mathrm{H}$ acceptor), with the methyl group oriented upwards (Bahr et al., 2008). A Monte Carlo study (Partay et al., 2007) characterized the solvation free-energy profiles for fifteen different small organic and inorganic solutes at the water/vapor and ice/vapor interfaces. The free-energy gain of adsorption relative to the isolated state of the solute molecule was found to be larger for solutes that are able to form stronger or more hydrogen bonds with the water molecules at the surface. It was also found to be independent of the state (i.e., liquid versus frozen) of the condensed phase; this was attributed to the presence of the DI. Comparable results have also been obtained with many other oxygenated VOC species, such as acetaldehyde (Petitjean et al., 2009), formic and acetic acids (Jedlovszky et al., 2008; von Hessberg et al., 2008; Symington et al., 2010), and alcohols (Kerbrat et al., 2007; Abbatt et al., 2008). A few studies have also shown that the coadsorption of a VOC with another trace gas onto the ice surface can be described well using a competitive Langmuir adsorption model (von Hessberg et al., 2008; Kerbrat et al., 2010) in the absence of chemically-induced surface changes (McNeill et al., 2006).

Few studies have directly addressed adsorption of nonoxygenated compounds, e.g., aromatic compounds, to ice, even though many of the persistent organic pollutants (POPs) may fall into this category. Aromatic species have been found via theoretical calculations to adsorb flat at the ice/air interface, optimizing the interaction of the delocalized $\pi$ electrons with the dangling hydrogens. This interaction is dominant compared to the mutual interaction of adsorbed aromatics (at sub-monolayer coverage). Domine et al. (2007) measured the equilibrium partitioning of phenanthrene to ice. Their observations, supported by molecular dynamics simulations, indicated electrostatic interactions between water and phenanthrene lying parallel to the ice surface. Fries et al. (2006) observed only weak reversible adsorption of several alkylbenzenes to dendritic ice crystals at $253 \mathrm{~K}$, even though their experiment was not designed to detect sub-monolayer coverage on the ice surface only. Abbatt et al. (2008) found that 
benzene adsorption follows the Langmuir model for a given temperature, but noted that the saturation surface coverage increases with increasing temperature.

At high surface coverage, adsorbate-adsorbate interactions may become important, especially for species capable of forming mutual hydrogen bonds. These have been suggested to affect the shape of measured adsorption isotherms, e.g., for formic and acetic acids (von Hessberg et al., 2008; Symington et al., 2010), as well as ethanol and acetone (Abbatt et al., 2008; Starr et al., 2011). For aromatics, selfassociation of naphthalene and anthracene at the gas-ice interface has been suspected from spectroscopic investigations (Kahan and Donaldson, 2007, 2008, 2010; Kahan et al., 2010) and supported by molecular dynamics investigations (Ardura et al., 2009). In a joint experimental and theoretical study (Heger et al., 2011), the adsorption of two 1methylnapthalene molecules to hexagonal ice, as a model of artificial snow, was simulated at $77 \mathrm{~K}$ and $239 \mathrm{~K}$ using classical molecular dynamics. It was found that the adsorbates tend to lie flat on the surface at $77 \mathrm{~K}$, but their mutual weak interactions are more important at $239 \mathrm{~K}$. Various structures of dimers were calculated and their calculated emission spectra were matched with those experimentally found.

Adsorbates can increase the thickness of the DI. Molecular dynamics simulations and experimental observations suggest that this increase can be most pronounced at or even limited to the close environment of the adsorbate (BartelsRausch et al., 2012). While so far this has been mostly discussed in the context of strong inorganic acids (Huthwelker et al., 2006; McNeill et al., 2006; McNeill et al., 2007; Krepelova et al., 2010), this also holds for organic trace gases. Bluhm et al. (2002) noted an effect of the presence of organic contaminants on surface disorder as determined by electron spectroscopy. This however, critically depends on the temperature and concentration. For acetone, Starr et al. (2011) did not observe changes to the local hydrogen bonding environment of the top most molecular layers between 220 and $250 \mathrm{~K}$. Molecular dynamics simulations (Liyana-Arachchi et al., 2011) also indicate that increasing the naphthalene concentration has a negligible effect on the DI thickness. It should be noted that laboratory observations of irreversible uptake of trace gases to ice (e.g., in flow tube experiments) cannot unequivocally be interpreted as evidence of DI growth unless supported by direct measurements of the DI. Other effects, such as the formation of hydrates, may explain the observed irreversible uptake, as pointed out by Symington et al. (2010) for the case of trifluoroacetic acid and also shown in a Raman study of formaldehyde frozen solutions by Chazallon et al. (2005).

Additionally, few experimental studies exist which directly probed the effect of the DI on the uptake of organic species. McNeill et al. (2006) studied the coadsorption of acetic acid and $\mathrm{HCl}$ on ice, and observed enhanced uptake of acetic acid under conditions where they observed $\mathrm{HCl}-$ induced DI formation via ellipsometry. Sokolov and Abbatt
(2002) also observed that the saturation surface coverage for $\mathrm{CH}_{3} \mathrm{COOH}$ on smooth polycrystalline ice films increased by a factor of $\sim 1.6$ above $243 \mathrm{~K}$ (conditions where the DI is likely to be present). Recent molecular simulations suggest that increasing the DI thickness contributes to efficiently stabilizing the interactions of each monomer with the ice surface as well as between the monomers. Liyana-Arachchi et al. (2011) looked at the co-adsorption of naphthalene and ozone at the ice surface close to the melting point. A significant uptake of naphthalene on the ice surface can hinder the direct adsorption of ozone at the air/ice interface. As the concentration of ozone increases, most of the naphthalene molecules still prefer to lie close to the mobile water molecules.

Based on experimental and theoretical evidence as summarized above, a quantitative description of adsorptive partitioning of organic trace gases to snow requires knowledge of the microscopic properties of the ice phase. In general these are given by the temperature and by the level of contaminants (Bartels-Rausch et al., 2012): A low temperatures (below $245 \mathrm{~K}$ or so) and low contaminant levels, uptake from the gas-phase can be well described as adsorption to the solid ice surface. The DI, the extent of which is minimal at these low temperatures (Bartels-Rausch et al., 2012), does not influence the uptake process. Experimental evidence clearly shows that with an increased disorder, either at higher temperatures or due to high levels of contaminants, the uptake of organics significantly increases, in some cases even a longterm, irreversible loss to the ice was observed. This behavior resembles somehow the uptake to the liquid phase and the parameterization of this is essentially an open question (Bartels-Rausch et al., 2012). Here, we briefly compare parameterization of the uptake of organics to ice based on adsorption to a solid ice surface and based on solution on the ice surface.

If the specific surface area is known, partitioning can be described by the corresponding equilibrium parameters. Since adsorption kinetics is often not critical for snow chemistry, it is usually sufficient to describe the adsorption equilibrium in terms of a gas-solid partitioning coefficient, $K_{\text {LinC. }} K_{\text {LinC }}$ describes the equilibrium in the linear regime of coverage versus concentration, i.e., at low gas phase concentrations (the label $\mathrm{C}$ refers to the fact that concentration (and not pressure) based units are used).:

$$
K_{\mathrm{LinC}}=\frac{[\mathrm{X}]_{\mathrm{s}}}{[\mathrm{X}]_{\mathrm{g}}}
$$

where $[\mathrm{X}]_{\mathrm{S}}$ and $[\mathrm{X}]_{\mathrm{g}}$ are the concentrations of species $\mathrm{X}$ on the surface (in molecules $\mathrm{cm}^{-2}$ ) and in the gas phase (in molecules $\mathrm{cm}^{-3}$ ), respectively. $K_{\mathrm{LinC}}$ is related to the thermodynamic equilibrium constant, described by the ratio of the number of molecules on the surface to that of molecules 
in the gas phase under standard conditions by:

$$
K_{\mathrm{LinC}}=K_{p}^{0} \frac{V}{A}=\exp \left(-\frac{\Delta G_{\mathrm{ads}}^{0}}{R T}\right) \frac{V}{A}
$$

where $\Delta G_{\text {ads }}^{0}$ is the free energy of adsorption, $V$ is the standard molar volume in the gas phase, and $A$ the standard molar area $\left(3.74 \times 10^{7} \mathrm{~m}^{2} \mathrm{~mol}^{-1}\right)$. The latter standard state has been suggested originally by Kemball and Rideal (1946), later used by Donaldson and Anderson (1999), and now also adopted by the IUPAC Subcommittee on Gas Kinetic Data Evaluation (Crowley et al., 2010). This group has evaluated $K_{\text {LinC }}$ values from laboratory data for a range of organic compounds.

We present data available for relevant organic compounds in the form of a plot of their free energy of condensation $\left(\Delta G_{\text {gas-liquid }}\right)$ at $228 \mathrm{~K}$ and their Henry's Law constant $(\mathrm{H})$ in water at $298 \mathrm{~K}$ vs. $\Delta G_{\text {ads }}^{0}$ (Fig. 2). Values of $\Delta G_{\text {ads }}^{0}$ based on the $K_{\text {LinC }}$ values as recommended by Crowley et al. (2010) are shown. $\Delta G_{\text {gas-liquid }}$ at 228 $\mathrm{K}$ was adopted from Pouvesle et al. (2010) and Henry's Law constants were obtained from Betterton and Hoffmann (1988) (acetaldehyde), Betterton (1991) (acetone), Johnson et al. (1996) (formic and acetic acids), and Yaws (2003) (methanol, ethanol, and butanol). Similar to what was observed by Sokolov and Abbatt (2002), there is a good correlation between $\Delta G_{\text {ads }}^{0}$ and $\Delta G_{\text {gas-liquid }}$ for the entire group of VOCs for which data were available. This group includes alcohols, aldehydes, ketones, and organic acids. The correlation between $\Delta G_{\text {ads }}^{0}$ and $\mathrm{H}$ is not as strong. One interpretation is that, for the range of conditions and sample types studied, the intermolecular forces governing the uptake process more closely resemble those of condensation than dissolution. This is consistent with laboratory observations of Langmuir-type adsorption. However, Ulrich et al. (2012) recently showed that $K_{\text {LinC }}$ for multiple acidic species correlates with both $\mathrm{H}$ and pKa. Mmereki et al. (2000) also compared the enthalpies of adsorption to those of solvation and vaporization. This analysis led them to conclude that "surface solvation" explained the enthalpy results better than condensation. Molecular modeling studies also suggest that $\Delta G_{\text {ads }}^{0}$ should be correlated with solubility (Partay et al., 2007).

Physical Henry's Law constants were used in our analysis; effective Henry's Law constant values may be higher for acetaldehyde or the organic acids depending on $\mathrm{pH}$ and ionic strength. This would worsen the apparent correlation between $\Delta G_{\text {ads }}^{0}$ and H. Finally, we note that the use of a Henry's Law constant involves the implicit assumption that there is a linear relationship between gas phase and liquid phase concentrations. Barret et al. (2011b) showed that this is not true in the case of formaldehyde, but rather, $\mathrm{H}$ varied as a function of concentration (see Eq. 4 in Sect. 3.2.3). Further studies of the dependence of $\mathrm{H}$ on concentration should be performed for higher aldehydes and other oxygenated organics.

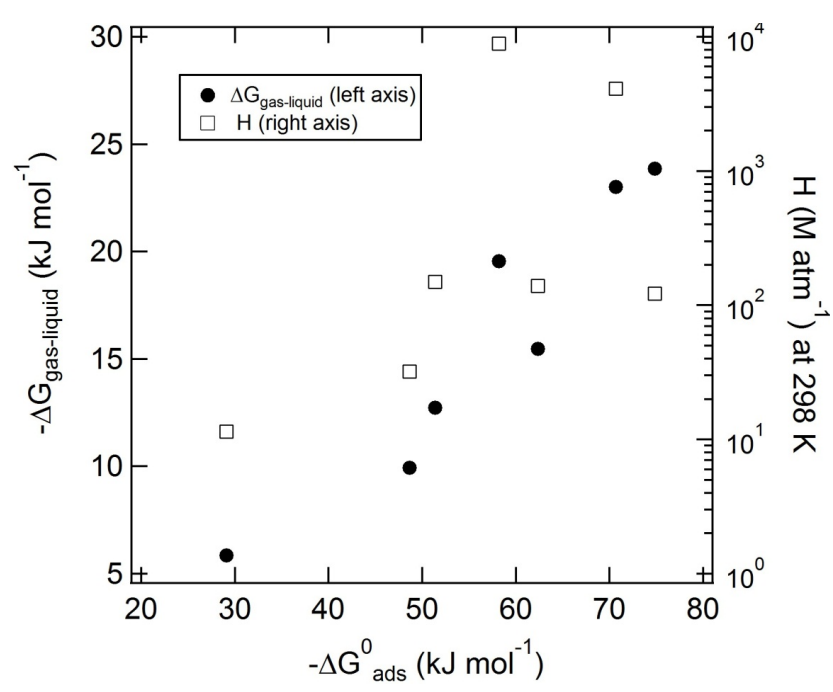

Fig. 2. Summary of standard Gibbs free energy of adsorption $\left(\Delta \mathrm{G}_{\mathrm{ads}}^{0}\right.$, see Eq. 2) data for organic species on ice, shown along with the free energy of condensation at $228 \mathrm{~K}, \Delta \mathrm{G}_{\text {gas-liquid }}$, and the Henry's law constant for pure water at $298 \mathrm{~K}, \mathrm{H}$. From left to right, the symbols are data for acetaldehyde, acetone, methanol, formic acid, ethanol, acetic acid, and 1-butanol. See text for details.

\section{The effects of adsorption and desorption on trace gas transport through snow}

Snow is a porous medium and transport of trace gases through the interstitial air is a prerequisite for fluxes between the snowpack and the overlaying air. The transport through the pore space can either be diffusive, i.e., driven by a concentration gradient, or advective, i.e., traces gases are transported by an interstitial airflow (wind pumping). One direct consequence of adsorption of organic trace gases to snow is that their diffusive transport through the snowpack may be slowed down. Diffusion is ubiquitous in natural snow (Domine et al., 2008) and dominates the transport of trace gases at low surface wind velocities (Albert and Shultz, 2002). A longer residence time also increases the likelihood that trace gases will participate in photochemistry within the snowpack.

The changes in diffusion of trace gases through porous media such as snow due to the reduced open volume and the interactions of the trace gas with the surface may be expressed using the effective diffusivity, $D_{\text {eff }}$. By use of $D_{\text {eff }}$, the diffusive flux of a trace gas through porous snow can be modeled, similarly to diffusion through homogeneous media, using Fick's first law of diffusion. $D_{\text {eff }}$ depends on the diffusion coefficient of the trace gas in air $\left(D_{\mathrm{g}}\right)$; geometric parameters of the snow that describe the open pore space, such as porosity $(\varphi)$ and tortuosity $(\tau)$; the available surface area, given by the specific surface area of the snow (SSA) and the ice to air volume ratio $\left(r_{\mathrm{sp}}\right)$; and the gas-solid partitioning coefficient 
$\left(K_{\text {LinC }}\right)$ (derived by Herbert et al. (2006b)):

$D_{\text {eff }}=D_{\mathrm{g}} \times \frac{\phi}{\tau} \times \frac{1}{1+r_{\mathrm{sp}} \times K_{\mathrm{LinC}} \times \mathrm{SSA}}$

The last term in Eq. (3) gives the fraction of trace gases in the pore space and thus reflects influences of trace gassurface interactions. As Domine et al. (2008) illustrated, the influence of adsorption on diffusion is only significant for strongly adsorbing species $\left(K_{\mathrm{LinC}}>10^{-3} \mathrm{~m}\right.$ for typical snowpacks with $r_{\mathrm{sp}}=0.2$ and SSA $=20 \mathrm{~m}^{2} \mathrm{~kg}^{-1}$ ). Phenanthrene falls into this category (Domine et al., 2007). For more volatile organics, gas-surface interaction is not expected to influence diffusion significantly. This general conclusion is also supported by field measurements of the transport behavior of semi-volatile organics in snowpacks (Herbert et al., 2006a, b). Herbert et al. (2006b), however, also found that calculated diffusion profiles based on the air-ice interaction as given by the $K_{\mathrm{LinC}}$ value leads to slower diffusivities than actually observed for a set of chlorinated organics. As temperatures of the snowpack in this study were near the melting point of ice, the authors suggested that liquid-air partitioning as given by the Henry's Law coefficient might better describe the snow-air interaction. While this approach might be motivated by the presence of the DI at such high temperatures, it is in clear contrast to the observation by Roth et al. (2004), who found that, at $266 \mathrm{~K}$, the partitioning to snow of nonpolar organic trace gases is strongly underestimated by the air-water partitioning coefficient, assuming a DI thickness of $1-50 \mathrm{~nm}$. The conclusion of Roth et al. (2004) is also supported by field measurements of snow concentrations of semi-volatile organics (Herbert et al., 2006b)

\subsubsection{Dissolution into brine}

Brine, which can be present to tens of degrees below the melting point of pure ice, changes the uptake of trace gases to snow or ice significantly (Bartels-Rausch et al., 2012). It is today widely assumed that the partitioning of gas-phase species into brine at the ice surface follows Henry's law, with the same parameters as one would use for equilibrium between a gas and a bulk liquid phase of the same composition as the brine. Approaches based on equilibrium thermodynamics for modeling the volume fraction of brine in the ice sample are available in the literature (Cho et al., 2002; Kuo et al., 2011). When significant incorporation of solute into the ice matrix is expected (see the following section), partitioning among all three phases (gas, brine, and ice matrix) should be accounted for (Kuo et al., 2011). Where the necessary data are available (parameterizations for Henry's Law constant, activity coefficient, and solubility in the ice matrix), organic species may be modeled in the same fashion as inorganic species. Related to this discussion are experiments by Petitjean et al. (2009), which showed increased, solubility-driven uptake of acetaldehyde in the presence of $\mathrm{HNO}_{3}$ under conditions where it may form a brine at the ice surface, consistent with observations for ethanol (Kerbrat et al., 2007) and acetone (Journet et al., 2005).

\subsubsection{Solid solution and diffusion through ice crystals}

Besides adsorbing at the surface, dissolving into an interfacial layer, or existing at grain boundaries or inclusions, trace gases may also be incorporated into the ice matrix. From a thermodynamic point of view, solid solutions of ice can be treated similarly to water solutions, with the solubility of gases expressed as a function of temperature and gas partial pressure. The solubility of gases in ice can be characterized by an absolute solubility (in $\mathrm{M}$ or as a mole fraction) or as an ice/water partition coefficient, i.e., the concentration ratio between both phases in thermodynamic equilibrium. Incorporating molecules or ions into the ice crystalline lattice involves structural constraints which are much more important in ice than water. As a result, typical solubilities in ice are orders of magnitude lower than in water. Intuitively, only small molecules can be accommodated in the ice crystalline lattice. Thermodynamics of solid solutions strictly apply to single crystals and the physical state of the ice must therefore be considered when interpreting field or laboratory measurements.

Early studies reported that large organic molecules such as glucose (Halde, 1980) and carboxymethyl cellulose (Smith and Pounder, 1960) could be incorporated within ice samples. However, this conclusion was reached by freezing liquid solutions, most likely under non-equilibrium conditions. It is therefore likely that these molecules were incorporated at grain boundaries or in pockets of trapped highly concentrated liquid solutions, rather than within the ice crystalline lattice. Methanesulphonic acid (MSA), a product of the atmospheric oxidation of dimethysulfide, has been analyzed in Antarctic ice cores and used for a proxy of sea ice extent (Curran et al., 2003). It has been assumed, more or less implicitly, that MSA formed a solid solution with ice and that it could diffuse through solid ice, which would explain its loss during ice core storage. Roberts et al. (2009) estimated its diffusion coefficient in solid ice to be $4.1 \times 10^{-13} \mathrm{~m}^{2} \mathrm{~s}^{-1}$, orders of magnitude higher than the single-crystal diffusion coefficients that have been measured for $\mathrm{HCl}, \mathrm{HNO}_{3}$, and HCHO ((Thibert and Domine, 1997, 1998; Barret et al., 2011b) and even for the self-diffusion coefficient of water in ice (Ramseier, 1967). Therefore, this value most likely does not represent diffusion of this large molecule through the ice crystal, but rather transport through triple junctions and grain boundaries. The high apparent solubility of MSA in ice $(\sim 0.1 \mu \mathrm{M}$, of the same order as HCHO and the nitrate ion) also supports the notion that MSA may be located at grain boundaries or triple junctions, rather than in a solid solution with ice.

.Fries et al. (2007) studied the incorporation of alkylbenzenes into growing ice crystals and attributed the uptake to volume processes, even though they could not conclude that 
they formed a solid solution, and instead suggested that they could be "included as small liquid droplets inside or between the crystals". Typical mole fractions found at $252 \mathrm{~K}$ for partial pressures of $2 \times 10^{-4} \mathrm{~Pa}$ were $3 \times 10^{-12}$, i.e., 3300 times lower than for $\mathrm{HCHO}$ under the same conditions. We hypothesize here that these alkylbenzenes could have been trapped within the crystalline lattice during growth, as consistent with the kinetic model of Domine and Thibert (1996), therefore forming a solid solution that is most likely highly supersaturated (i.e., a metastable, nonequilibrium situation). We also speculate that the large size of these molecules would prevent them from diffusing out of the ice.

The only organic molecule for which the existence of a solid solution with ice has been conclusively demonstrated is HCHO. Barret et al. (2011b) proposed the following equation for the equilibrium mole fraction of $\mathrm{HCHO}$ in ice, $X_{\mathrm{HCHO}}$,ice, as a function of temperature $T(\mathrm{~K})$ and $\mathrm{HCHO}$ partial pressure $P_{\mathrm{HCHO}}(\mathrm{Pa})$ :

$X_{\mathrm{HCHO}, \text { ice }}=9.898 \times 10^{-13} e^{(4072 / T)}\left(P_{\mathrm{HCHO}}\right)^{0.803}$

Under typical atmospheric conditions with $\mathrm{P}_{\mathrm{HCHO}}$ in the range $10^{-6}$ to $2 \times 10^{-4} \mathrm{~Pa}$ (i.e., mixing ratios of 10 2000 pptv), the predicted solubility is in the range $10^{-10}$ to $3 \times 10^{-8}$ mole fraction (i.e., $0.17-5.1 \mathrm{ppbw}$ ). In comparison, the $\mathrm{HCHO}$ concentration in polar snow is in the range 0.2-13 ppbw (Hutterli et al. 1999, 2003; Perrier et al., 2002; Barret et al., 2011a), indicating that HCHO in polar snow is not far from equilibrium with the atmosphere. Perrier et al. (2002) and Barret et al. (2011a) calculated the snowpack loading in $\mathrm{HCHO}$ at Alert (Canadian Arctic, $82^{\circ} \mathrm{N}$ ) and Barrow (Alaska, $71^{\circ} \mathrm{N}$ ) and found values in the range 20 to $60 \mathrm{ng} \mathrm{m}^{-2}$. This was found to be 5-200 times greater than in the atmospheric boundary layer, illustrating that the Arctic seasonal snowpack represents a significant $\mathrm{HCHO}$ reservoir.

Barret et al. (2011a, b) showed that equilibration of $\mathrm{HCHO}$ in surface snow layers with the atmosphere proceeds via solid state diffusion, with a time constant of several days (Fig. 3). They were able to reproduce the measured time evolution of $X_{\mathrm{HCHO}}$ by calculating diffusion of $\mathrm{HCHO}$ in and out of snow crystals, using their measured value of the diffusion coefficient of HCHO in ice, $D_{\mathrm{HCHO}}=6 \times 10^{-16} \mathrm{~m}^{2} \mathrm{~s}^{-1}$ independent of temperature within measurement error, the snow grain size deduced from measurement of specific surface area, and the measured time series of $P_{\mathrm{HCHO}}$.

Carbonyls larger than HCHO, such as acetaldehyde, acetone, glyoxal and methylglyoxal have been measured in polar snow (Houdier et al., 2002; Domine et al., 2010, 2011; Douglas et al., 2012), at concentrations somewhat lower but of the same order of magnitude as those of HCHO. In the case of acetone, Houdier et al. (2002) note that the measured concentrations are much too high to be explained by adsorption, and that the size of the molecule makes incorporation into the ice crystalline lattice unlikely. They suggest instead that acetone is incorporated into organic particles contained in the snow. In the case of acetaldehyde, Domine et al. (2010)

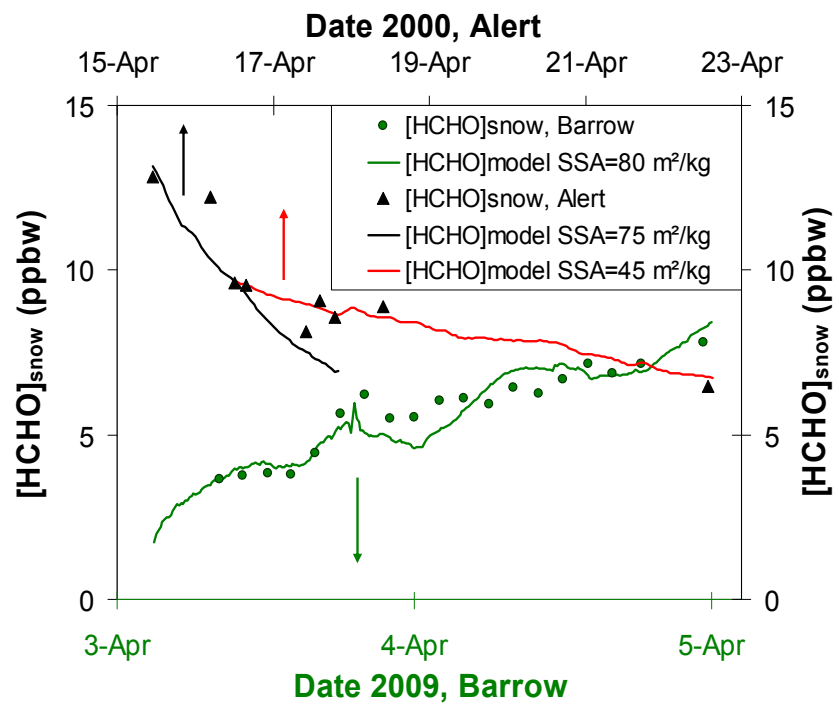

Fig. 3. Interpretation of changes in the HCHO concentration, $[\mathrm{HCHO}]_{\text {snow }}$ in surface snow at Alert in 2000 and at Barrow in 2009 , by solid state diffusion of $\mathrm{HCHO}$ in and out of snow crystals, after Barret et al (2011a, b). Based on time series of $\mathrm{P}_{\mathrm{HCHO}}$, on the specific surface area (SSA) of the snow, Barret et al. modeled [HCHO] and found a good agreement between modeled and measured values. SSA was kept constant in the Barrow case, as variations were small over 2 days. For the Alert case, 2 values were used to account for changes over 7 days, as the model does not allow SSA continuous variations.

conclude that either this molecule is also contained in the organic particles, or that its detection is an artifact due to the hydrolysis of larger molecules when the snow is melted for analysis. These conclusions can probably be applied to the heavier glyoxal and methylglyoxal. Available evidence therefore indicates that among carbonyls, only the lightest one, $\mathrm{HCHO}$, can form a solid solution with ice, with equilibrium concentrations that can explain field measurements. The equilibrium incorporation of larger molecules into the ice crystal lattice appears unlikely to explain their measured concentration. Other molecules whose small size could allow the formation of a solid solution include $\mathrm{CH}_{4}, \mathrm{CH}_{3} \mathrm{OH}$, $\mathrm{HCOOH}$ and $\mathrm{CH}_{3} \mathrm{Cl}$. No detailed studies of their interactions with ice under atmospheric conditions are available. Given the low solubilities of $\mathrm{CH}_{4}$ and $\mathrm{CH}_{3} \mathrm{Cl}$ in water (Yamamoto et al., 1976; Moore et al., 1995), it is unlikely that they would form a solid solution with ice. Methanol and formic acid deserve further study, especially given that they have been measured in snowpack interstitial air and/or in melted snow samples (Legrand and Deangelis, 1995; Boudries et al., 2002; Dibb and Arsenault, 2002).

\subsection{Chemical transformations}

In the following section we provide an overview of the mechanisms for chemical transformation of semivolatile and 
non-volatile organic compounds in ice and snow, or on their surfaces.

\subsubsection{Frozen aqueous solutions}

The freezing of aqueous solutions of most organic and inorganic compounds results in separation of ice and solute molecules, which increases the local solute concentrations in a liquid layer covering the ice crystal surface or in micropockets or microveins within the ice. This is known as the freeze-concentration effect. Such a highly concentrated mixture may completely solidify below the eutectic point of the system (Pincock, 1969).

In order to evaluate the extent of the concentration effect when aqueous solutions of organic compounds are frozen, aggregation of methylene blue was studied using absorption spectroscopy (Heger et al., 2005). This compound is known to self-organize to produce sandwich-type associations exhibiting a blue shift of the spectral band of the $\pi, \pi^{*}$ transition compared to that of a monomer (Lewis et al., 1943). It was found that the methylene blue local concentrations were enhanced by 3-4 orders of magnitude upon fast freezing at $77 \mathrm{~K}$, and by more than by 6 orders of magnitude upon slow freezing at $243 \mathrm{~K}$, compared to that in liquid solutions.

Heger et al. (2006) showed that a simple concentration effect was responsible for enhanced protonation of cresol red, an organic acid-base indicator, in frozen aqueous solutions containing various acids, such as $\mathrm{HF}, \mathrm{HCl}, \mathrm{HNO}_{3}, \mathrm{H}_{2} \mathrm{SO}_{4}$, and $p$-toluene sulfonic acid. The study, which was conducted using UV-visible absorption spectroscopy between -20 and $-196^{\circ} \mathrm{C}$, revealed that production of a protonated form of cresol red was enhanced by 2-4 orders of magnitude upon freezing compared to that in liquid solutions. It was concluded that the effect was related to an increase in the microscopic concentration of acids in the proximity of the indicator, due to the freeze-concentration effect. On the contrary, $\mathrm{NaOH}$ (in $\mathrm{NaCl}$ or $\mathrm{NaOH}$ ) caused cresol red to dissociate (Heger et al., 2006).

In a related study, Robinson et al. (2006) studied pH changes in brine remaining upon freezing of solutions using solid-state nuclear magic angle spinning (SS-MAS) NMR of the ${ }^{19} \mathrm{~F}$ chemical shift $\left({ }^{19} \delta\right)$ of 3 -fluorobenzoic acid (3-FBA). It was observed that upon freezing a solution of $10 \mathrm{mM} \mathrm{3-}$ FBA in 1.06 molal $\left(\mathrm{NH}_{4}\right)_{2} \mathrm{SO}_{4}$, the $\mathrm{pH}$ of the remaining liquidus in the brine decreases at lower temperatures. The increase in $\mathrm{pH}$ observed when freezing a $1 \mathrm{M} \mathrm{NaCl}$ solution at lower temperatures suggested that concentration effects were not the main factor controlling the acidity shift. The raise and drop in $\mathrm{pH}$ observed at lower temperatures indicates that the observed process occurs in a fluid domain existent within the bulk solid phases. In agreement with the observations of Workman and Reynolds (1950) during the freezing of $\left(\mathrm{NH}_{4}\right)_{2} \mathrm{SO}_{4}$ and $\mathrm{NaCl}$ solutions, respectively, the sign of the acidity changes was related to the incorporation of ions to the ice phase. The preferential incorporation of $\mathrm{NH}_{4}^{+}$and
$\mathrm{Cl}^{-}$into the ice matrix relative to their rejected counter-ions $\mathrm{SO}_{4}^{2-}$ and $\mathrm{Na}^{+}$affects the transport of $\mathrm{H}^{+}$and $\mathrm{HO}^{-}$ions out of or into the ice. The finding was confirmed using a solution of a zwitterionic buffer, which did not change its acidity upon freezing (Robinson et al., 2006).

Donaldson and coworkers compared the air-ice and airwater interfaces using Raman spectroscopy at glancing angle of the OH-stretch bands. The protonation of acridine, an organic fluorescent $\mathrm{pH}$ probe, at the air-ice interface was observed in the presence of $\mathrm{HNO}_{3}$ or $\mathrm{HCl}$ deposited to the ice surface from vapors (Kahan et al., 2007; Wren and Donaldson, 2012). However, no enhancement in the proton concentration was observed at the interface upon freezing mildly acidic or neutral solutions. The authors concluded that dissociation of acids may occur within the DI. The release of hydroxide anion in the heterogeneous ozonation of bromide at sea-ice surfaces was also confirmed using harmine, another pH-sensitive fluorescent probe (Wren et al., 2010).

Time-resolved confocal fluorescence microscopy showed that the morphology and composition of interstitial fluids in polycrystalline ice is affected by electrolytes as observed during the freezing of 4-(10-(dimethylamino)-3-oxo-3H-benzo[c]xanthen-7-yl)isophthalic acid (a pH probe). The relatively thick $(12 \mu \mathrm{m})$ glassy channels observed upon freezing the $10 \mu \mathrm{M}$ probe in water became random inclusions with less than $1 \mu \mathrm{m}$ diameter in the presence of $1 \mathrm{mM}$ sodium chloride. The $30 \mu \mathrm{L}$ frozen sample of $1 \mathrm{mM} \mathrm{NaCl}$ had an interstitial volume of $13.2 \mathrm{~nL}$ (or $0.044 \%$ volume fraction) at $-5^{\circ} \mathrm{C}$. This morphology change was attributed to the dynamic instabilities produced by the rejected solute in the freezing front rather than by thermodynamics (Cheng et al., 2010).

Steady-state and time-resolved emission techniques have been employed to study the photoprotolytic cycle of excited photoacids on methanol-doped ice samples (Uritski and Huppert, 2008; Uritski et al., 2009a, b). The experimental results indicated that the proton diffusion constant in ice is larger than that in water.

It has been shown that freezing alone, without any alkaline reagent dopant, can be a unique method of promoting base-catalyzed reactions under neutral or acidic conditions. (It should be noted that this refers to the $\mathrm{pH}$ of the bulk solution prior to freezing). For example, the base catalyzed decomposition of gallic acid in frozen solutions is promoted by the addition of $\mathrm{NaCl}$ to the bulk solution under neutral and acidic conditions $\left(\mathrm{pH}_{\text {fluid }}=4.5\right)$ prior to freezing. Upon freezing, the ice lattice incorporates more $\mathrm{Cl}^{-}$than $\mathrm{Na}^{+}$ions (Workman and Reynolds, 1950). The migration of $\mathrm{H}_{3} \mathrm{O}^{+}$ion from the unfrozen solution to the ice allows the system to return to a charge-neutral state. The $\mathrm{pH}$ of the unfrozen portion, as a consequence, increases by $\sim 3$ units and catalyzes the alkaline decomposition of gallic acid (Takenaka et al., 2006). The electrochemical potential which results between the ice and remaining unfrozen solution is known as the WorkmanReynolds freezing potential (Workman and Reynolds, 1950). 
The effect of temperature and solute concentration on the nucleophilic aromatic substitution reaction of $p$-nitroanisole with pyridine was studied in frozen aqueous solutions. Reaction rates were enhanced up to $\sim 40$-times at temperatures down to $236 \mathrm{~K}$ due to freeze concentration (Grannas et al., 2007a). Reaction rates were dependent on temperature and ionic strength. The results obtained indicate that a significant portion of the organic solutes are excluded to liquid-like layers or micropockets, but that the amount excluded is dependent on the liquid-like fraction present in the sample. A model to explain the freezing concentration effect on the rate enhancement of reactions has been proposed (Takenaka and Bandow, 2007).

\subsubsection{Photophysics and photochemistry}

Environmental ice and ice surfaces provide a unique medium for the photochemistry of organic species. Two types of photochemical processes may occur in environmental ices: direct photochemistry and/or indirect photoinduced transformations. Direct photochemistry occurs when the organic species features one or more chromophores, i.e., it directly absorbs incoming radiation, leading to possible photochemical breakdown of the compound. Indirect photochemistry occurs when another species (known as a photosensitizer) absorbs radiation, subsequently transferring electronic energy to or exchanging electrons with another moiety which becomes either an excited species or radical intermediate, which in turn undergoes intra- or intermolecular transformations (Klan and Wirz, 2009). Secondary chemical reactions can also be triggered by the presence of reactive species, such as radicals, formed by direct irradiation of photoinitiators. Important photoinitiators include nitrate, nitrite, peroxides and organic matter.

For direct photochemical processes, the optical properties of organic compounds, the local illumination conditions, and the quantum yields of their chemical reactions in ice determine their photochemical reactivity. The nature and magnitude of the intermolecular interactions of some dipolar organic solvatochromic indicators in frozen solutions at 253 or $77 \mathrm{~K}$ were studied using empirical solvent polarity parameters (Heger and Klan, 2007). A solvatochromic effect originates from a different degree of solvent molecule orientation around a dipolar probe in the ground state, and from the dipole moment change when the probe is electronically excited. Hydrogen-bond and electron-pair donating ice-contaminant interactions were found to be considerably larger than those in liquid aqueous solutions, which was demonstrated by shifts in the probe absorption maxima upon freezing. Recent findings have also indicated that the absorption spectra of simple aromatic compounds, such as phenol derivatives (Matykiewiczova, 2007b) or benzene (Kahan and Donaldson, 2010), exhibit bathochromic shifts to wavelengths that overlap with those of solar radiation at an air-ice interface. This may be due to self-association of hydropho- bic compounds at the air-ice interface (Kahan and Donaldson, 2007; Ardura et al., 2009; Kurkova et al., 2011; Heger et al., 2011) giving rise to shifts in their electronic absorption spectra in some cases. Using a combination of resolved fluorescence spectroscopy and molecular dynamics simulations, Ardura et al. (2009) demonstrated a strong propensity for naphthalene (and by extension, other hydrophobic compounds) to self-associate at the air-ice interface, but not (except at very high concentrations) at the air-liquid water interface.

Cerenkov radiation from cosmic muons may also play a role in ice photochemistry. It is hypothesized to account for the anomalous $\mathrm{CO}$ and $\mathrm{CO}_{2}$ levels found in some Greenland ice core records, which exceed those in contemporaneous Antarctic records by up to $130 \mathrm{ppbv}$ and $20 \mathrm{ppmv}$, respectively (Haan and Raynaud, 1998; Tschumi and Stauffer, 2000). A comparison of the organic content in both polar ice caps shows that the Greenland ice cores are enriched by the organic aerosol released in major boreal forest fires during the last two millennia (Gayley and Ram, 1985; Kawamura et al., 1995; Desideri et al., 1998; Savarino and Legrand, 1998). Hoffmann and coworkers found that the photodegradation of dissolved organic matter trapped in ice cores by ultraviolet Cerenkov radiation from cosmic muons can account for the anomalous $\mathrm{CO}$ and $\mathrm{CO}_{2}$ levels, and the correlation between them (Colussi and Hoffmann, 2003; Guzman et al., 2007; Guzman, 2007).

The oxidation of organic compounds by reactive species photochemically generated in ice or snow can be an important mechanism of their degradation. A number of studies have illustrated that important photooxidation processes can occur in/on environmental ices, and that observed rates and mechanisms may differ from what is observed in corresponding liquid samples. The irradiation of frozen aqueous solutions containing chlorophenols and hydrogen peroxide (as a source of hydroxyl radicals) resulted in formation of chlorobenzenediols or dihydroxybenzenes (Klanova et al., 2003b). Observed competition of the different photoreaction mechanisms was explained by the fact that both chlorophenols and $\mathrm{H}_{2} \mathrm{O}_{2}$ are photoactive chromophores. Aromatic and saturated aliphatic hydrocarbons and their derivatives can also be oxidized in the presence of $\mathrm{H}_{2} \mathrm{O}_{2}$ upon irradiation (Dolinova et al., 2006). When phenol or 4-methoxyphenol were photolyzed in frozen solutions in the presence of inorganic nitrite or nitrate, nitration, hydroxylation, as well as radical coupling reactions were observed as the major degradation processes (Matykiewiczova et al., 2007b). The photochemical decomposition of 4-nitrophenol produced nitrate, nitrite, hydroquinone, benzoquinone, and 4-nitrosophenol, and was found to occur with similar quantum yields in both water and ice (Dubowski and Hoffmann, 2000). Recently, Gao and Abbatt (2011) reported the mechanism of organic dicarboxylic acid oxidation by $\mathrm{OH}$ in frozen solutions. The freezing drove variable separation of the reactants, which dramatically affected the kinetics of different 
di-acids, dependent on their solubility. In the only experiments to probe reactions between hydroxyl radicals and organic species directly in the DI, Kahan et al. (2010) reported significant suppression of reactivity compared to that measured in aqueous solution or in bulk ice samples. This was the case both when $\mathrm{OH}$ was formed through the photolysis of precursors such as $\mathrm{H}_{2} \mathrm{O}_{2}$, nitrate, or nitrite also present in the $\mathrm{DI}$, and when $\mathrm{OH}$ was deposited from the gas phase. Although it could be that the $\mathrm{OH}$ and organics were present in different regions of the ice surface, the enhanced reaction rate at the ice surface as compared to the air-aqueous interface reported by the same authors using ozone as the oxidant (vide infra) suggests that this may not be the whole story. Molecular dynamics calculations of the fate of $\mathrm{OH}$ and its reactivity on an ice surface would certainly help to address this issue.

Rowland et al. (2011) conducted field-based experiments in Barrow, Alaska investigating the photochemical degradation of organochlorine contaminants. They found that this process is more efficient in ice than aqueous solution and that natural sensitizers present in snowpack (particularly natural organic matter) may play an important role in the photochemical fate of anthropogenic compounds. Photochemical degradation rates for aldrin and dieldrin (frozen in MilliQ water, $500 \mu \mathrm{M}$ hydrogen peroxide solution or locally-collected snow) were determined and significant photoprocessing of both pesticides occurred. The degradation was dependent on temperature, depth within the snowpack and whether the predominant phase of the sample was ice or liquid water. The photosensitizing effect of species present in natural snowpack was comparable to $500 \mu \mathrm{M}$ hydrogen peroxide, pointing to the potential significance of snowpack-mediated reactions in the environment. Samples frozen at near 273K were more reactive than comparable liquid samples, implying that the microenvironments experienced on frozen ice surfaces are an important consideration for pollutant reactivity.

Ram and Anastasio (2009) observed in lab-based studies significant direct and indirect photodegradation of phenanthrene, pyrene, and fluoranthene in frozen aqueous solutions with and without added hydrogen peroxide (a source of $\mathrm{OH}$ radical). Weber et al. (2009) investigated photolytic degradation of organophosphorus pesticides in ice and found the reaction efficiencies to be far higher in ice than in liquid solution in some cases. Recent laboratory studies have shown that rates of photooxidation of aromatics present at the airice interface are enhanced with respect to the reaction at the air-liquid water interface (Kahan and Donaldson, 2007, 2010; Kahan et al., 2010b,c). Some (but not all) of this increase may be attributed to spectral shifts giving rise to increased overlap with the excitation source (Kahan and Donaldson, 2007, 2010). The rate increase is clearly associated with compounds present in the interface region, as demonstrated by a rate increase as the surface/volume ratio of the ice sample is increased (Kahan et al., 2010c). Additionally, Kahan et al. (2010a) showed that the rate of reaction could be "tuned" from that at the air-pure ice interface (fast) to that at the water interface (slow) by freezing salt water solutions of successively greater concentration. This gives rise to increasing amounts of a liquid-like brine layer at the interface, and changes the corresponding photolysis kinetics to that seen at salt water interfaces. These results suggest that direct photolysis could be an important removal pathway for organic pollutants in snow-covered regions, for example, in polar or urban areas contaminated by oil spills or leaks, and that the presence of other contaminants may affect photochemical fates by altering the ice surface environment (c.f. Kahan et al. 2010a).

Unexpected photochemical reactions of halobenzenes, such as chlorobenzene, 2- or 4-dichlorobenzene, bromobenzene, or 1,4-dibromobenzene, in frozen aqueous solutions have been reported (Klan et al., 2000, 2001; Klan and Holoubek, 2002). Photolysis of relatively concentrated $\left(c>10^{-4} \mathrm{~mol} \mathrm{~L}^{-1}\right)$ solutions frozen below approximately $265 \mathrm{~K}$ gave dehalogenation, coupling (halogenated biphenyls or terphenyls derivatives), or rearrangement products, instead of photosolvolysis products (phenols) which are produced in irradiated samples above this temperature or in liquid aqueous solutions. Predominant coupling product formation is related to a substantial concentration effect and still efficient diffusion of reactive reaction intermediates. Similarly, chlorobiphenyldiols were shown to be the major products produced by UV-irradiation of halophenols in frozen solutions (Klanova et al., 2003a, b).

Photochemical behavior of persistent organic pollutants, such as polychlorinated biphenyls (PCBs), in artificial snow at environmentally relevant concentrations has been studied in order to monitor chemical changes occurring at the iceair interface (Matykiewiczova et al., 2007a). It was demonstrated that PCBs underwent reductive dehalogenation reactions upon irradiation at $\lambda>290 \mathrm{~nm}$, which were in competition with a desorption process responsible for the pollutant loss from snow, especially in the case of lower molecularmass derivatives produced during photolysis.

\subsubsection{Electron transfer processes in ice}

Electron transfer processes, by which electrons move from one chemical species to another with a change in oxidation states of both reagents involved, may be facilitated in ice. At cryogenic temperatures, the freeze concentration effect is complemented by the lack of mobility of the solutes in the solid matrix that provides a fixed frame for electron transfer to occur (Guzman et al., 2006). At the warmer temperatures of the environment, electron transfer may occur in the restricted environment of a DI or liquidlike region of the ice (Guzman et al., 2006a, 2007). An intermolecular electron transfer reaction in ice was observed during the irradiation $(\lambda=320 \pm 10 \mathrm{~nm})$ of pyruvic acid in frozen solutions. Two types of triplet distant radical pairs, consistent with $\mathrm{n}-\pi^{*}$ excitation of pyruvic acid, were produced in the primary photoprocess. The transition induces 
long-range intra-dimer and inter-dimer electron transfer from the excited carbonyl chromophore to neighboring carbonyl acceptors. The decarboxylation of primary radical ion pairs ${ }^{3}\left[\mathrm{CH}_{3} \mathrm{COCOOH}^{+\bullet} \ldots \mathrm{CH}_{3} \mathrm{COCOOH}^{-\bullet}\right]$ accounted for the observed release of $\mathrm{CO}_{2}$ (Guzman et al., 2006a). Electron transfer processes initiated by organic chromophores are not limited to organic species as electron acceptors. The heterogeneous conversion of $\mathrm{NO}_{2}$ into $\mathrm{HONO}$ on ice films was significantly enhanced in the presence of humic acid upon irradiation at visible wavelengths. The reaction between the organic material and the adsorbed $\mathrm{NO}_{2}$ requires a light absorbing sensitizer $(\mathrm{S})$ to promote the electron transfer from reduced (e.g., phenolic) moieties in humic acid to $\mathrm{NO}_{2}$. Reactive excited state species $\mathrm{S}^{*}$ and $\mathrm{NO}_{2}^{-}$are generated, and the latter undergoes protonation to $\mathrm{HONO}$. The reaction showed a linear production of HONO for increasing irradiation intensity and humic acid surface concentration, but no temperature dependence from 260 down to $215 \mathrm{~K}$ (Bartels-Rausch, 2010). Similarly, Beine et al. (2008) observed an increase in HONO production from illuminated natural snow doped with humic acid between 260 and $273 \mathrm{~K}$. The photoreduction of mercuric ions in a thin ice film is also enhanced in the presence of organics such as benzophenone and oxalic acid (Bartels-Rausch et al., 2011). The reaction showed a linear temperature trend from $240 \mathrm{~K}$ up to a liquid solution at $273 \mathrm{~K}$.

The heterogeneous oxidation of dissolved organic matter in ice was proposed to occur on the surface of goethite $(\alpha-\mathrm{FeOOH})$, or other metal oxyhydroxides (Guzman, 2007). Related experiments to study the heterogeneous photodissolution $(\lambda>300 \mathrm{~nm})$ of $\mathrm{Fe}(\mathrm{III})$ to $\mathrm{Fe}(\mathrm{II})$ were conducted for frozen $(253 \mathrm{~K})$ solutions of hematite $\left(\alpha-\mathrm{Fe}_{2} \mathrm{O}_{3}\right)$, maghemite $\left(\gamma-\mathrm{Fe}_{2} \mathrm{O}_{3}\right)$, and goethite, in the presence of organic acids electron donors (Kim et al., 2010). The enhanced dissolution of $\mathrm{Fe}$ (III) in ice compared to the fluid sample is due to a photoinduced process. The same dissolution trend to produce soluble Fe(II) was observed, with a slower rate, for visible light with wavelengths greater than $400 \mathrm{~nm}$ (Kim et al., 2010).

Another redox conversion studied in polycrystalline ice ($20^{\circ} \mathrm{C}$ ) is the reduction of hexavalent $\mathrm{Cr}(\mathrm{VI})$ (as chromate) to $\mathrm{Cr}(\mathrm{III})$ in the presence of organic acid electron donors:

$2 \mathrm{HCr}^{\mathrm{VI}} \mathrm{O}_{4}^{-}+3 \mathrm{HOOC}-\mathrm{COOH}+8 \mathrm{H}^{+} \rightarrow 2 \mathrm{Cr}^{3+}+6 \mathrm{CO}_{2}+8 \mathrm{H}_{2} \mathrm{O}$

The enhancement in concentrations of $\mathrm{Cr}(\mathrm{VI})$ ) electron donor, and $\mathrm{H}^{+}$in the several $\mu \mathrm{m}$ thick ice crystal grain boundaries accelerated the rate of reaction to values that are comparable to fluid solutions with $\sim 100$-times larger $\mathrm{Cr}(\mathrm{VI})$, electron donor, and $\mathrm{H}^{+}$concentrations (Kim and Choi, 2011).

\subsubsection{Cage effect}

The cage effect describes how the properties or chemical reactions of a given compound are affected by the immediate surroundings it experiences. In a bulk solution, molecules are typically influenced by the surrounding "cage" of solvent molecules. If a molecule undergoes photolytic dissociation, the process of recombination will be in competition with diffusion out of the cage. These cage effects may be very different in bulk liquid solution, frozen solutions, or at air-ice interfaces. For example, at the air-ice interface the solvent cage is incomplete and recombination reactions may be inhibited as a result.

The photochemical reaction of dibenzyl ketone has historically been used as a probe to assess the efficacy of a given medium as the "cage" and as a way to investigate the mobility of molecules in solution or at surfaces (Ramamurthy, 1986). The Norrish type I reaction of 4-methyldibenzyl ketone was used to study the cage effect in frozen aqueous solutions over a temperature range of 193-273 K (Ruzicka et al., 2005). The heterogeneous environments present in the frozen solutions caused a remarkable cage effect on the product formation due to restricted diffusion of the radical intermediates. The cage effect was found to increase consistently with decreasing temperature, and eventually leveled off to $100 \%$ at temperatures below $203 \mathrm{~K}$ (Fig. 4; dashed curve). The data allowed estimation of the temperature $(223 \mathrm{~K})$ at which the rates of radical diffusion and recombination become equal (the inflection point depicted as $\mathrm{I}_{1}$ in Fig. 4). It was hypothesized that while water molecules of ice (acting as Hbond donors or acceptors) are expected to restrict the motion of polar compounds, the diffusion of non-polar benzyl radicals is only affected by relatively weak polar $\pi$-interactions, phase, microviscosity, hydrophobic forces (Scatena et al., 2001), and degree of the disorder at the gas-ice interface (Kurkova et al., 2011). Additionally, the dynamics of recombination/dissociation of benzyl radical pairs, photochemically produced from 4-methyldibenzyl ketone was studied on artificial as well as natural snow surfaces (Kurkova et al., 2011). The inflection point at approximately $257 \mathrm{~K}$ obtained for artificial snow was substantially different from that obtained for frozen solution (Fig. 4). Thus compared to frozen aqueous solutions, in which the physical constraints of the ice matrix represent a 3-dimensional cage, the restrictions imposed on the ice crystal surface were suggested to be visualized as a 2-dimensional cage (Kurkova et al., 2011).

Pyruvic acid is present as hydrogen-bonded dimers that are randomly spread in the ice matrix (Guzman et al., 2006a). The rate of $\mathrm{CO}_{2}$ evolution from the photolysis of frozen aqueous pyruvic acid solutions showed no change when 2,2,6,6-tetramethylpiperidinyl-1-oxy (TEMPO) free radical scavenger was added prior to freezing. This was interpreted as mobility restrictions preventing the radical scavenger action of TEMPO. All photolytic radical intermediates escaped the cage and reacted irreversibly above $190 \mathrm{~K}$ (Guzman et al., 2006a), in several mechanistic steps to produce 2,3-dimethyltartaric acid and 2-(3-oxobutan-2-yloxy)-2hydroxypropanoic acid (Guzman, 2007). The results of Guzman et al. (2006a) agree with those of Ruzicka et al. (Fig. 4) 


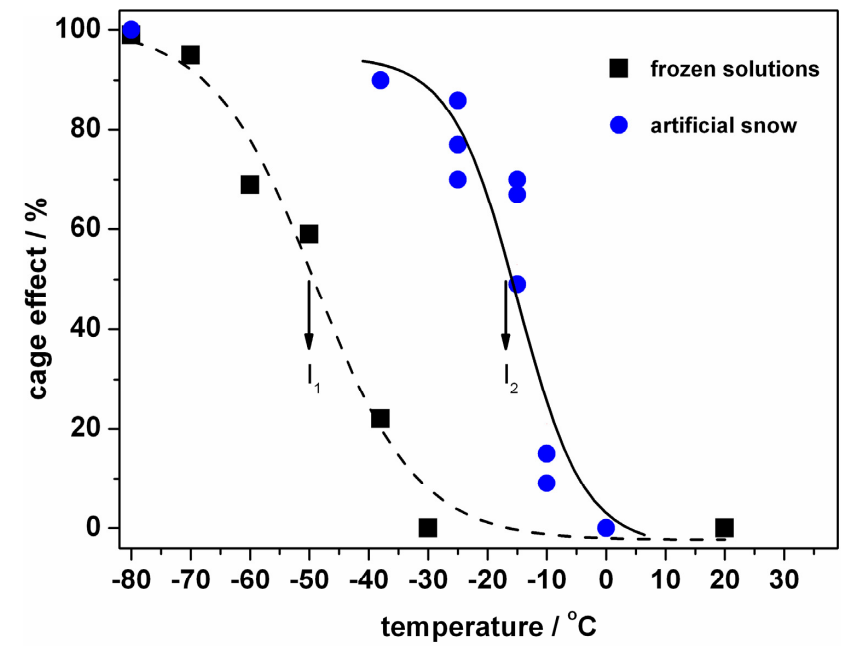

Fig. 4. The cage effect, determined for frozen and artificial snow samples. The inflection points $\left(\mathrm{I}_{1}\right.$ and $\left.\mathrm{I}_{2}\right)$ are the temperatures at which the rates of radical diffusion and recombination become equal (Ruzicka et al., 2005; Kurkova et al., 2011).

up to $\sim 190 \mathrm{~K}$, but above this temperature they differ because the initially formed radical ions $\mathrm{PA}^{+\bullet}$ and $\mathrm{PA}^{-} \bullet$ do not retain their identity. Specifically, the radical cation, $\mathrm{PA}^{+\bullet}$, undergoes deprotonation followed by ultrafast decarboxylation, concomitantly with photon absorption, of the resulting acylcarbonyloxyl radicals: $\left[\mathrm{CH}_{3} \mathrm{C}(\mathrm{O}) \mathrm{C}(\mathrm{O}) \mathrm{OH}\right]^{+\bullet} \stackrel{-H^{+}}{\longrightarrow}$ $\mathrm{CH}_{3} \mathrm{C}(\mathrm{O}) \mathrm{C}(\mathrm{O}) \mathrm{O} \rightarrow \mathrm{CH}_{3} \mathrm{C}(\mathrm{O})+\mathrm{CO}_{2}$, rendering a different species above $190 \mathrm{~K}$. Differential scanning calorimetry measurements, during the warming cycle, showed a single endotherm at the colligatively depressed melting point of water (Guzman et al., 2006c). Therefore, at high temperatures (e.g., $>235 \mathrm{~K}$ ) this reaction proceeds in restricted liquid-like regions (Guzman et al., 2006a, 2007).

\subsubsection{Oligomerization chemistry}

Organic compounds with large Henry's law constants, and typically large oxygen content, partition preferentially into the aqueous-phase of organic aerosols, where they remain, given their low volatility and polar character (Saxena and Hildemann, 1996). Among these ubiquitous atmospheric organics there are hygroscopic, low-molecular-weight, watersoluble dicarbonyls, dicarboxylic acids, and $\alpha$ - and $\omega$ oxocarboxylic acids (Kawamura et al., 2001), many of which are known oxidation products of biogenic and/or anthropogenic hydrocarbons. The uptake of these species to aqueous aerosols, followed by aqueous-phase oligomerization reactions, is a source of secondary organic aerosol material (SOA) (Hallquist et al., 2009). The SOA material generated is often "humic-like" in character, in that it is high molecular weight, light absorbing, and surface-active (Graber and Rudich, 2006; Noziere et al., 2007; Shapiro et al., 2009; Sareen et al., 2010; Schwier et al., 2010). It is possible that similar oligomerization chemistry occurring in brines, DI, or in aerosols trapped in the snow could be a source of light-absorbing, high molecular weight organics in ice and snow. The oligomerization of $\alpha$-dicarbonylic compounds was demonstrated to form high molecular weight complex organic matter with similar optical properties to atmospheric HULIS in laboratory mimics of aqueous aerosol and environmental ices (Guzman et al., 2006b, 2007; Rincon et al., 2009, 2010). The radical mechanism is initiated via photoinduced electron transfer between triplet excited state and ground-state pyruvic acid to produce a bound radical ion pair (Scheme A). The propagation steps (Scheme B) involve the addition of radicals $\mathrm{X}^{\bullet}$ and $\mathrm{Y}^{\bullet}$ to pyruvic acid and/or oligomer products, even in the presence of air because the oxyl radical $\mathrm{Y}^{\bullet}$ is not scavenged by $\mathrm{O}_{2}$. The same mechanism was operative in liquid and ice (Guzman et al., 2007). Beine et al. (2011) measured the absorbance of melted filtered snow in Barrow, Alaska and found that HULIS was the largest contributor to absorbance, even though they only represent $10 \%$ of DOC (Voisin et al., 2012).

\subsection{6 $\mathrm{O}_{3}$ oxidation chemistry}

The heterogeneous reaction of phenanthrene with gasphase ozone at the air-ice interface was studied by Kahan and Donaldson (2008). This reaction exhibits a LangmuirHinshelwood dependence on gas phase $\left[\mathrm{O}_{3}\right]$, consistent with a surface-mediated reaction. The rate constant at any given $\left[\mathrm{O}_{3}(\mathrm{~g})\right]$ was significantly faster than that measured at a room temperature air-octanol interface.

Klan and coworkers measured the kinetics of ozonation reaction of 1,1-diphenylethylene in artificial snow, produced by shock freezing of the aqueous solutions sprayed into liquid nitrogen (Ray et al., 2011). It was demonstrated that most of the reactant molecules are in direct (productive) contact with gaseous ozone, thus the technique produces snow with organic molecules largely ejected to the surface of snow grains. The experimental results were consistent with the Langmuir-Hinshelwood type reaction mechanism. The kinetic data were used to evaluate the snow specific surface area as a measure of the availability of the molecules on the surface for chemical reaction with gaseous species.

\subsection{Biological sources/sinks}

The chemical and physical characterization of organic and bio-organic materials is of prime importance in understanding the global carbon cycle (Muyzer and van der Kraan, 2008). Environmental processes involving carbon species of anthropogenic and biogenic origins have shown to be complex, and crossing disciplines (Ariya et al., 2011). The source, conversion and fate of organic material is often linked to microbial activity, because organics can serve as substrates, nutrients, and exudates for a large number of genera that then produce organic metabolites with yet again different 


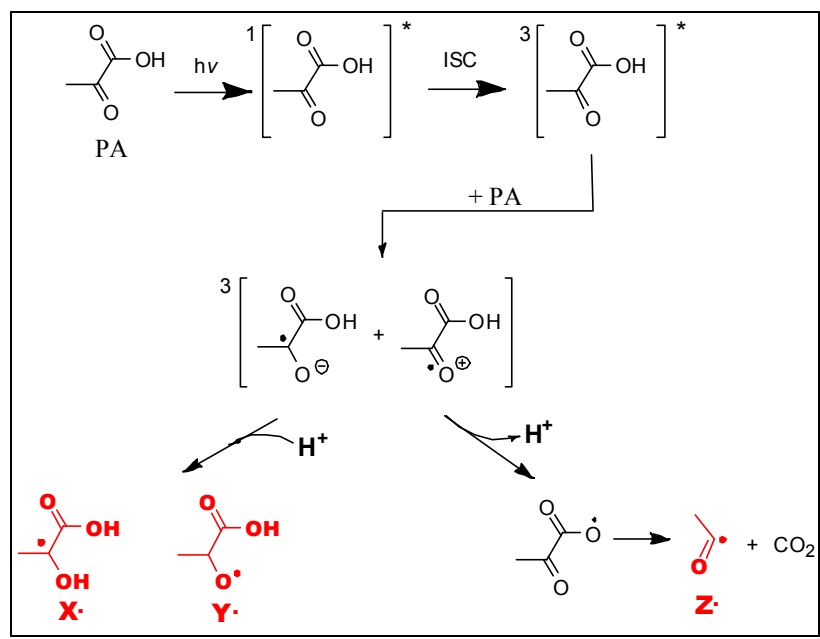

Scheme A. Initiation steps of the pyruvic acid oligomerization mechanism, after Guzman et al. (2006b, 2007) and Rincon et al. (2009, 2010). See text for details.

properties (Le Borgne et al., 2008). Bacteria and fungi were shown to oxidize methane, benzene, and toluene in soil and snowpack as a result of metabolic activity (Lee et al., 2010). Bio-organic materials (e.g., algae bloom) are known to affect the snow color (Bej et al., 2010) and therefore reflectivity (albedo) of snow surfaces. Moreover, as potential contributors to organic aerosols, their role in atmospheric radiation and climate should not be ignored.

The importance of biomaterial to atmospheric chemistry and climate is not only demonstrated for the moderate and warm climates, but there is also a solid body of evidence for the existence of substantial amount of taxa in both Arctic and Antarctic regions (Bej et al., 2010). Bacteria, algae and other microorganisms, including extremophiles, have been increasingly identified in the snowpack (Felip et al., 1995; Thomas and Dieckmann, 2002; Amato et al., 2007; Mortazavi et al., 2008; Ariya et al., 2011). Researchers have been investigating the role of microorganisms in atmospheric and terrestrial processes, for example in ice nucleation (Mortazavi et al., 2008), cloud condensation (e.g., Bauer et al., 2003), species transfer (Starokozhev et al., 2011) and metabolization of nutrients (Ariya et al., 2002; Buckeridge and Grogan, 2008). Processes previously assumed to be almost exclusively driven by photochemistry, physical deposition and re-volatilization, can also have microbiological origins (Ariya et al., 2011). While the role of micro-organisms in cloud formation has received increasing attention during the last decades (Szyrmer and Zawadzki, 1997; Sun et al., 2010), the importance of metabolizing microorganisms in the snowpack, sea ice and frost flowers is only emerging, as methodologies and technologies are being developed to deal with the complexity of the sample matrices. At the moment, the existing techniques are generally tedious, often yielding in- complete characterization of the microbiological population. Hence, it is difficult to decipher adequately the extent of biotic processes that can occur simultaneously in snow.

The metabolization of VOCs by bacteria and fungi has long been studied (Walker et al., 1976). Numerous laboratory studies have shown the degradation of anthropogenic and sometimes very toxic compounds by microbial species (Hickman and Reid, 2008). Bioremediation effectively uses these processes to provide optimal growth conditions to accelerate degradation rates (Timmis and Pieper, 1999). Sorption of some organic pollutants to bacterial cells or exudates have also been discussed (Bengtsson et al., 1993; Ariya et al., 2011), processes that are potentially applicable to microorganisms in snow as well. There are very limited data in the literature from concurrent VOC and microbial snow measurements. Mortazavi and coworkers (2012) found a significant amount of culturable bacteria and fungi in a variety of snow types and frost flowers in Barrow, AK during OASIS 2009. They also sampled and measured VOCs such as toluene, xylenes, and acetophenone. While anthropogenic influence cannot be ruled out, the apparent enrichment of acetophenone suggests a connection with biochemical activity. Further studies, for example, including isotopic probes, are required to shed light on mechanistic pathways of microbial biochemical interactions with VOCs in snow.

The importance of biomaterials in physico-chemical processes in frost flowers is little understood. Frost flowers are ubiquitous on the thin layer of sea ice that grows over refreezing sea ice leads. They are delicate, featherlike ice crystals that form over a period of hours to days and have a high brine content. Frost flowers have been suggested to act as a source of $\mathrm{BrO}$ to the atmosphere, a species that contributes to surface ozone depletion events (Kaleschke et al., 2004). These very salty ice crystals are also a source of sea-salt aerosol (Perovich and Richter-Menge, 1994) to the atmosphere. Studies of the organic content of frost flowers using infrared spectroscopy showed a distinct anthropogenic influence and detection of alkane-type and oxidized species (Shaw et al., 2010). Increased bacterial abundance was also detected in frost flowers (Bowman and Deming, 2010). Beine et al. (2012) studied frost flowers using UVVis spectrophotometry. They found that the absorption coefficients, attributable mostly to light-absorbing organics, were 40 times greater for frost flowers than for land snow. To our knowledge there are only very limited studies on bio-organic materials in frost flowers. Mortazavi et al. (2012) observed viable cultivable bacteria and fungi, along with enrichment of ${ }^{238} \mathrm{U}$ and $\mathrm{CHBr}_{3}$ in frost flowers.

\section{Impact of environmental ices on local, regional and global carbon cycles}

Environmental ices play a significant role in the cycling and chemistry of organic carbon on local, regional and global 


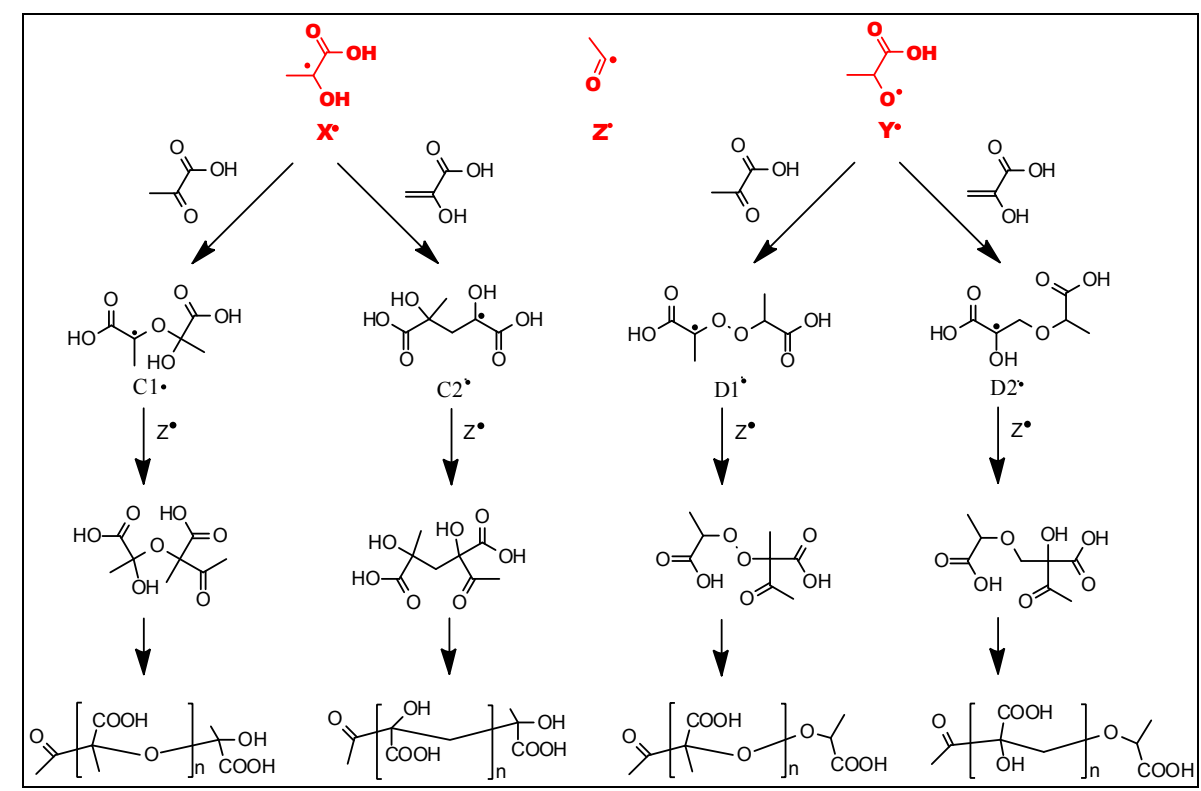

Scheme B. Propagation steps of the pyruvic acid oligomerization mechanism after Guzman et al. (2006b, 2007) and Rincon et al. (2009, 2010). See text for details.

scales. A variety of connections exist between atmospheric, oceanic and terrestrial ices, all of which will be susceptible to alterations due to climate change. In this section we illustrate where such connections may exist but we emphasize that making definitive conclusions on the role of organic-ice interactions on the carbon cycle, for example, is premature for this young discipline. Further discussion of the role of the cryosphere in the global transport and processing of persistent organic pollutants can be found in a separate review in this Special Issue (Grannas et al., 2012).

As examples, we note that sea ice can act as a reservoir of organic carbon, a barrier to air-sea exchange of volatile and semi-volatile organic gases, and a substrate for chemical and biological processes at the air-ice interface, within the sea ice, and at the underlying ice-sea interface. Climate change has resulted in significant loss of sea ice extent and thickness, as well as a shift from perennial ice cover (greater than one year old) to seasonal ice less than a year old (Perovich, 2011). Sea ice loss will result in greater air-sea gas exchange, potential changes to biological and photochemical activity due to loss of substrate and redistribution of previously deposited/stored organic carbon from sea ice to the seawater or atmosphere. In some cases the magnitude and direction of these changes are not well understood due to the interconnections between the physical, chemical and biological processes that affect organic carbon.

Glacier ice is another component of the cryosphere that influences carbon cycling and is susceptible to climate change. Anthropogenic contaminants, such as persistent organic pollutants, deposited to glaciers (and typically stored in the ice) will be delivered to surrounding ecosystems upon glacier melt (Bogdal et al., 2010). This process will be particularly important on the local scale, where high altitude/mountain lakes are the direct recipients of glacial run-off. Also, glacierderived dissolved organic matter represents a highly bioavailable source of carbon to downstream ecosystems (Hood et al., 2009). The sources of this organic matter can include the remnants of terrestrial organic matter overrun by glaciers (Bardgett et al., 2007; Hood et al., 2009; Bhatia et al., 2010), in situ microbial processes (Pautler et al., 2011) and deposition of anthropogenic aerosol (Stubbins et al., 2012). If the organic material is released during glacial melt (which is accelerating due to climate change), it may alter the carbon cycle of surrounding aquatic environments, potentially by stimulating microbial activity.

Frost flowers are an important, yet poorly understood interface between the atmosphere and sea ice. It has been shown that organic molecules can become incorporated in (and concentrated in/on) frost flowers during their growth (Douglas et al., 2012). The high surface area of frost flowers, combined with the high concentrations of potentially reactive species present in the frost flowers, result in a chemically active medium in/on which organic compounds could be altered. The organics could become reincorporated into sea ice, transported with wind-blown frost flowers, or released to the atmosphere. Once in the atmosphere, the organic compounds could play a role in secondary aerosol formation. Unfortunately, none of these processes have been studied in detail.

Snow, over both marine and terrestrial environments, influences the fate of organic carbon on a number of scales. Snow is an excellent scavenger of volatile and semi-volatile organic compounds with a range of 
physicochemical properties (Wania et al., 1999; Lei and Wania, 2004). Snow-air partition coefficients are temperature dependent, so the degree to which snowfall-scavenging occurs will be determined by temperature, an effect evidenced in the organic contaminant concentration gradients observed along elevational gradients (e.g., Blais et al., 1998; Arellano et al., 2011). The geographic distribution of organic contaminants in a number of alpine and Arctic parks in North America could only be explained by including the temperature dependent impact of snow-air partitioning, along with the magnitude of local contaminant sources (Hageman et al., 2010). The exchange of organic compounds between snow and the atmosphere will be influenced by the nature of the snowpack (surface area, thermal gradients, depth) as well as wind ventilation of the snowpack. In all but the most extreme cold environments, snowpack is subject to seasonal melting. Seasonal snowmelt will deliver organics to the surrounding ecosystem, often in a concentrated pulse (Meyer and Wania, 2008 , 2011). This could serve to deliver a highly concentrated load of chemicals to the surrounding ecosystem. These chemicals may be toxic in the case of snowpack influenced by contaminant deposition, or they may be biologically available organic or inorganic nutrients. Since the properties and metamorphism of snow are influenced by temperature, these processes (snow deposition, metamorphism and melt) will be highly susceptible to changes in a warming climate, at both polar and mid-latitudes, which will in turn impact the cycling and fate of organic carbon associated with snow.

\section{Outlook and further questions}

Ultimately, a model of transport and transformations of organic material in the cryosphere is needed in order to predict the effects of climate change on the fate of pollutants, regional atmospheric chemistry, and the Earth's carbon cycle, and the associated impacts on the rest of the Earth system. Despite the growing body of knowledge summarized here regarding the sources, chemistry, and properties of organic material in environmental ices, we still lack fundamental insight necessary to develop such a model. Besides significant gaps in our understanding of the physics and chemistry of the interactions of organic material with environmental ices, the roles of biota and other compartments in the Earth system are still poorly constrained. A full understanding of this system requires interdisciplinary work at the interfaces of several traditionally disparate fields, including physics, chemistry, biology, atmospheric sciences, glaciology, oceanography, and soil biogeochemistry (Williams et al., 2009; Ariya et al., 2011; Shepson et al., 2012).

Advances in analytical techniques are necessary to better qualify and quantify organic and bio-organic compounds in air and snow; for improved monitoring of their concentrations, emissions and fluxes; and to avoid any possible artifact from the analytical procedure. For example, Domine et al. (2010) pointed out that acetaldehyde may be produced during the melting of snow samples prior to analysis, e.g., from precursors in organic aerosols trapped in the snow. This could clearly interfere with the measurement of free aldehydes in snow. Development of in situ methods to characterize (bio)chemical species, including oxygenated carbonyl compounds, in snow, without melting are required. Advanced techniques combining high-resolution microscopy and optical spectroscopy show much promise towards in situ understanding of chemical composition and physical characteristics of free organic species or those sequestered in complex aggregates, or in particles within the snow matrix

Outstanding questions exist regarding the state of the ice surface in typical environmental scenarios, as well as the rates, mechanisms, and microphysical location of key chemical reactions which affect the fate of organics in environmental ices. There is growing evidence that ice morphology and microphysics (brines, DI, microveins/micropockets, grain boundaries, etc.) strongly influence the processing of organic species in environmental snow and ices. For a full review of this subject please see Bartels-Rausch et al. (2012). The properties of these media and the rates and chemical mechanisms of processes occurring there are still poorly constrained. There is a need for basic physical chemistry data required to model partitioning among phases, including solubility and diffusion coefficients of organic species in the ice matrix, and parameterizations for the Henry's law constants and activity coefficients in brine. Despite its likely importance, relatively few studies exist to date in which the effects of ice microphysics on organic ice chemistry and air-ice chemical interactions were probed directly. Recent advances of inherently surface sensitive techniques confirm that the uptake of even highly water soluble organics has little impact on the formation of DI and the uptake can be well described as adsorption to solid surfaces at temperatures up to $245 \mathrm{~K}$ or so. Yet, once the disorder exceeds a certain level, increased uptake has been observed. In particular, very little direct information exists regarding the influence of the DI on the surface chemistry of ice, and feedbacks between the chemistry of organic species and interfacial layer properties. More laboratory studies in which ice microphysics and chemistry are characterized simultaneously are necessary in order to deconvolute the multiple physical and chemical processes which determine the fate of organic species in the cryosphere. Finally, there is a lack of fundamental laboratory and theoretical studies of the physics and chemistry of biomaterials in ice.

Acknowledgements. This manuscript arose from discussion during and following the 3rd Workshop on Air-Ice Chemical Interactions in June 2011, in New York, NY. This workshop was sponsored in part by IGAC and the Columbia University School of Engineering and Applied Sciences. V. F. M. wishes to acknowledge support from the NSF CAREER award (ATM-0845043). A. M. G. wishes to acknowledge support from the NSF CAREER award 
(ATM-0547435). J. P. D. A., D. J. D., and T. F. K. acknowledge NSERC and CFCAS for funding. M. A. and T. B. appreciate support by the Swiss National Science Foundation (grants 121857 and 125179). P. A. A. is grateful to NSERC, FQRNT, and CFI. Part of the work of F. D. and D. V. was supported by the French Polar Institute (IPEV). M. G.: Funding from the University of Kentucky is gratefully acknowledged. D. H.: The work was supported by the Grant Agency of the Czech Republic (203/09/P445). P. K.: The work was supported by the Grant Agency of the Czech Republic (P503/10/0947), and the project CETOCOEN (CZ.1.05/2.1.00/01.0001) granted by the European Regional Development Fund.

Edited by: E. Wolff

\section{References}

Abbatt, J. P. D.: Interactions of atmospheric trace gases with ice surfaces: Adsorption and reaction, Chem. Rev., 103, 4783-4800, 2003.

Abbatt, J. P. D., Bartels-Rausch, T., Ullerstam, M., and Ye, T. J.: Uptake of acetone, ethanol and benzene to snow and ice: effects of surface area and temperature, Environ. Res. Lett., 3, 045008, doi:10.1088/1748-9326/3/4/045008, 2008.

Adamson, A. W. and Gast, A. P.: Physical chemistry of surfaces, 6th Ed., Wiley, New York, USA, 571-591, 1997.

Albert, M. R. and Shultz, E. F.: Snow and firn properties and airsnow transport processes at Summit, Greenland, Atmos. Environ., 36, 2789-2797, 2002.

Amato, P., Hennebelle, R., Magand, O., Sancelme, M., Delort, A. M., Barbante, C., Boutron, C., and Ferrari, C.: Bacterial characterization of the snow cover at Spitzberg, Svalbard, FEMS Microbiol. Ecol., 59, 255-264, 2007.

Anastasio, C. and Robles, T.: Light absorption by soluble chemical species in Arctic and Antarctic snow, J. Geophys. Res., 112, D24304, doi:10.1029/2007JD008695, 2007.

Anderson, C. H., Dibb, J. E., Griffin, R. J., Hagler, G. S. W., and Bergin, M. H.: Atmospheric water-soluble organic carbon measurements at Summit, Greenland, Atmos. Environ., 42, 56125621, 2008.

Ardura, D., Kahan, T. F., and Donaldson, D. J.: Self-Association of Naphthalene at the Air-Ice Interface, J. Phys. Chem. A, 113, 7353-7359, 2009.

Arellano, L., Fernandez, P., Tatosova, J., Stuchlik, E., and Grimalt, J. O.: Long-range transported atmospheric pollutants in snowpacks accumulated at different altitudes in the Tatra Mountains (Slovakia), Environ. Sci. Technol., 45, 9268-9275, 2011.

Ariya, P. A., Domine, F., Kos, G., Amyot, M., Cote, V., Vali, H., Lauzier, T., Kuhs, W. F., Techmer, K., Heinrichs, T., and Mortazavi, R.: Snow - a photobiochemical exchange platform for volatile and semi-volatile organic compounds with the atmosphere, Environ. Chem., 8, 62-73, 2011.

Ariya, P. A., Nepotchatykh, O., Ignatova, O., and Amyot, M.: Microbiological degradation of atmospheric organic compounds, Geophys. Res. Lett., 29, 2077, doi:10.1029/2002GL015637, 2002.

Bahr, S., Toubin, C., and Kempter, V.: Interaction of methanol with amorphous amorphous solid water, J. Chem. Phys., 13, 134712, 2008.
Bardgett, R. D., Richter, A., Bol, R., Garnett, M. H., Baumler, R., Xu, X., Lopez-Capel, E., Manning, D. C., Hobbs, P. J., Hartley, I. R., and Wanek, W.: Heterotrophic microbial communities use ancient carbon following glacial retreat, Biol. Lett., 3, 487-490, 2007.

Barret, M., Houdier, S., and Domine, F.: Formaldehyde in the Alaskan Arctic snowpack: Partitioning and physical processes involved in air-snow exchanges, J. Geophys. Res.-Atmos., 116, D00R03, doi:10.1029/2011JD016038, 2011a.

Barret, M., Houdier, S., and Domine, F.: Thermodynamics of the Formaldehyde-Water and Formaldehyde-Ice Systems for Atmospheric Applications, Applications, J. Phys. Chem. A, 115, 307317, $2011 \mathrm{~b}$.

Bartels-Rausch, T., Guimbaud, C., Gaggeler, H. W., and Ammann, M.: The partitioning of acetone to different types of ice and snow between 198 and 223 K, Geophys. Res. Lett., 31, L16110, doi:10.1029/2004GL020070, 2004.

Bartels-Rausch, T., Brigante, M., Elshorbany, Y. F., Ammann, M., D’Anna, B., George, C., Stemmler, K., Ndour, M., and Kleffman, J.: Humic acid in ice: Photo-enhanced conversion of nitrogen dioxide into nitrous acid, Atmos. Environ., 44, 5443-5450, 2010.

Bartels-Rausch, T., Krysztofiak, G., Bernhard, A., Schlaeppi, M., Schwikowski, M., and Ammann, M.: Photoinduced reduction of divalent mercury in ice by organic matter, Chemosphere, 82 , 199-203, 2011.

Bartels-Rausch, T., Jacobi, H.-W., Kahan, T., Thomas, J., Thomson, E. S., Abbatt, J., Ammann, M., R. Blackford, J., Bluhm, H., Boxe, C., Domine, F., Frey, M. M., Gladich, I., Guzman, M. I., Heger, D., Huthwelker, Th., Klán, P., Kuhs, W. F., Kuo, M., Maus, S., Moussa, S., McNeill, V. F., Newberg, J. T., Pettersson, J. B. C., Roeselova, M., and Sodeau, J.: Relationship between snow microstructure and physical and chemical processes, in preparation, Atmos. Chem. Phys. Discuss., 2012.

Bauer, H., Giebl, H., Hitzenberger, R., Kasper-Giebl, A., Reischl, G., Zibuschka, F., and Puxbaum, H.: Airborne bacteria as cloud condensation nuclei, J. Geophys. Res.-Atmos., 108, 4658, doi:10.1029/2003JD003545, 2003.

Behr, P., Terziyski, A., and Zellner, R.: Acetone adsorption on ice surfaces in the temperature range $T=190-220 \mathrm{~K}$ : Evidence for aging effects due to crystallographic changes of the adsorption sites, J. Phys. Chem. A, 110, 8098-8107, 2006.

Beine, H. J., Anastasio, C., Esposito, G., Patten, K., Wilkening, E., Domine, F., Voisin, D., Barret, M., Houdier, S., and Hall, S.: Soluble, light-absorbing species in snow at Barrow, Alaska, J. Geophys. Res., 116 (D00R05), 116, D00R05, doi:10.1029/2011JD016181, 2011.

Beine, H. J., Colussi, A. J., Amoroso, A., Esposito, G., Montagnoli, M., and Hoffman, M. R.: HONO emissions from snow surfaces, Environ. Res. Lett., 3, 045005, 2008.

Beine, H. J., Anastasio, C., Domine, F., Douglas, T., Barret, M., France, J., King, M., Hall, S., and Ullmann, K.: Soluble chromophores in marine snow, snow, seawater, sea ice, and frost flowers near Barrow, Alaska, J. Geophys. Res., 117(D00R15), 117, D00R15, doi:10.1029/2011JD016650, 2012.

Bej, A. K., Aislabie, J., and Atlas, R.Polar Microbiology: The Ecology, Biodiversity and Bioremediation Potential of Microorganisms in Extremely Cold Environments. Informa Healthcare Publishing (Taylor and Francis/CRC Press). Boca Raton, FL, USA, 
2010.

Bengtsson, G., Lindqvist, R., and Piwoni, M. D.: Sorption of Trace Organics to Colloidal Clays, Polymers, and Bacteria, Soil Sci. Soc. Am. J., 57, 1261-1270, 1993.

Betterton, E. A.: The Partitioning of Ketones Between the Gas and Aqueous Phases, Atmos. Environ., 25, 1473-1477, 1991.

Betterton, E. A. and Hoffmann, M. R.: Henry Law Constants of Some Environmentally Important Aldehydes, Environ. Sci. Technol., 22, 1415-1418, 1988.

Bhatia, M. P., Das, S. B., Longnecker, K., Charette, M. A., and Kujawinski, E. B.: Molecular characterization of dissolved organic matter associated with the Greenland ice sheet, Geochim. Cosmochim. Acta, 74, 3768-3784, 2010.

Bizzotto, E. C., Villa, S., Vaj, C., and Vighi, M.: Comparison of glacial and non-glacial-fed streams to evaluate the loading of persistent organic pollutants through seasonal snow/ice melt, Chemosphere, 74, 924-930, 2009.

Blais, J. M., Schindler, D. W., Muir, D. C. G., Kimpe, L. E., Donaldk, D. B., and Rosenberg, B.: Accumulation of persistent organochlorine compounds in in mountains of Western Canada., Nature, 395, 585-588, 1998.

Bluhm, H., Ogletree, D. F., Fadley, C. S., Hussain, Z., and Salmeron, M.: The The premelting of ice studied with photoelectron spectroscopy, J. Phys.: Cond. Matter, 14, L227-L233, 2002.

Bogdal, C., Nikolic, D., Luthi, M. P., Schenker, U., Scheringer, M., and Hungerbuhler, K.: Release of legacy pollutants from melting glaciers: Model evidence and conceptual understanding, Environ. Sci. Technol., 44, 4063-4069, 2010.

Boudries, H., Bottenheim, J. W., Guimbaud, C., Grannas, A. M., Shepson, P. B., Houdier, S., Perrier, S., and Domine, F.: Distribution and trends of oxygenated hydrocarbons in the high Arctic derived from measurements in the atmospheric boundary layer and interstitial snow air during the ALERT2000 field campaign, Atmos. Environ., 36, 2573-2583, 2002.

Bowman, J. S. and Deming, J. W.: Elevated bacterial abundance and exopolymers in saline frost flowers and implications for atmospheric chemistry and chemistry and microbial dispersal, Geophys. Res. Lett., 37, L13501, doi:10.1029/2010GL043020, 2010.

Buckeridge, K. M. and Grogan, P.: Deepened snow alters soil microbial nutrient limitations in arctic birch hummock tundra, Appl. Soil Ecol., 39, 210-222, 2008.

Chazallon, B., Lebrun, N., Dhamlincourt, P., Toubin, C., and Focsa, C.: Micro-Raman investigations of the formaldehyde-ice system, J. Phys. Chem. B, 109, 432-439, 2005.

Cheng, J., Soetjipto, C., Hoffmann, M. R., and Colussi, A. J.: Confocal Fluorescence Microscopy of the Morphology and Composition of Interstitial Fluids in Freezing Electrolyte Solutions, J. Phys. Chem. Lett., 1, 374-378, 2010.

Cho, H., Shepson, P. B., Barrie, L. A., Cowin, J. P., and Zaveri, R.: NMR investigation of the quasi-brine layer in ice/brine mixtures, J. Phys. Chem. B, 106, 11226-11232, 2002.

Colussi, A. J. and Hoffmann, M. R.: In situ photolysis of deep ice core contaminants by Cerenkov radiation of cosmic origin, Geophys. Res. Lett., 30, 1195, doi:10.1029/2002GL016112, 2003.

Crowley, J. N., Ammann, M., Cox, R. A., Hynes, R. G., Jenkin, M. E., Mellouki, A., Rossi, M. J., Troe, J., and Wallington, T. J.: Evaluated kinetic and photochemical data for atmospheric chemistry: Volume V - heterogeneous reactions on solid substrates,
Atmos. Chem. Phys., 10, 9059-9223, doi:10.5194/acp-10-90592010, 2010.

Curran, M. A. J., vas Ommen, T. D., Morgan, V. I., Phillips, K. L., and Palmer, A. S.: Ice core evidence for Antarctic sea ice decline since the 1950s, Science, 302, 1203-1206, 2003.

Desideri, P. G., Lepri, L., Udisti, R., Checchini, L., Del Bubba, M., Cini, R., and Stortini, A. M.: Analysis of organic compounds in Antarctic snow and their origin, Int. J. Environ. Anal. Chem., 71, 331-351, 1998.

Dibb, J. E. and Arsenault, M.: Shouldn't snowpacks be sources of monocarboxylic acids?, Atmos. Environ., 36, 2513-2522, 2002.

Doherty, S. J., Warren, S. G., Grenfell, T. C., Clarke, A. D., and Brandt, R. E.: Light-absorbing impurities in Arctic snow, Atmos. Chem. Phys., 10, 11647-11680, doi:10.5194/acp-1011647-2010, 2010.

Dolinova, J., Ruzicka, R., Kurkova, R., Klanova, J., and Klan, P.: Oxidation of aromatic and aliphatic hydrocarbons by $\mathrm{OH}$ radicals photochemically generated from $\mathrm{H}_{2} \mathrm{O}_{2}$ in ice, Environ. Sci. Technol., 40, 7668-7674, 2006.

Domine, F. and Thibert, E.: Mechanism of incorporation of trace gases in ice grown from the gas phase, Geophys. Res. Lett., 23, 3627-3630, 1996.

Domine, F., Cabanes, A., and Legagneux, L.: Structure, microphysics, and surface area of the Arctic snowpack near Alert during the ALERT 2000 campaign, Atmos. Environ., 36, 27532765, 2002.

Domine, F. and Shepson, P. B.: Air-Snow Interactions and Atmospheric Chemistry, Science, 297, 1506-1510, 2002.

Domine, F., Sparapani, R., Ianniello, A., and Beine, H. J.: The origin of sea salt in snow on Arctic sea ice and in coastal regions, Atmos. Chem. Phys., 4, 2259-2271, doi:10.5194/acp-4-2259-2004, 2004.

Domine, F., Cincinelli, A., Bonnaud, E., Martellini, T., and Picaud, S.: Adsorption of phenanthrene on natural snow, Environ. Sci. Technol., 41, 6033-6038, 2007.

Domine, F., Albert, M., Huthwelker, T., Jacobi, H.-W., Kokhanovsky, A. A., Lehning, M., Picard, G., and Simpson, W. R.: Snow physics as relevant to snow photochemistry, Atmos. Chem. Phys., 8, 171-208, doi:10.5194/acp-8-171-2008, 2008.

Domine, F., Houdier, S., Taillandier, A.-S., and Simpson, W. R.: Acetaldehyde in the Alaskan subarctic snowpack, Atmos. Chem. Phys., 10, 919-929, doi:10.5194/acp-10-919-2010, 2010.

Domine, F., Gallet, J. C., Barret, M., Houdier, S., Voisin, D., Douglas, T., Blum, J. D., Beine, H. J., and Anastasio, C.: The specific surface area and chemical composition of diamond dust near Barrow, Alaska, J. Geophys. Res.-Atmos., 116, D00R06, doi:10.1029/2011JD016162, 2011.

Donaldson, D. J. and Anderson, D.: Adsorption of atmospheric gases at the air-water interface. 2. C-1-C-4 alcohols, acids, and acetone, J. Phys. Chem. A, 103, 871-876, 1999.

Douglas, T. A., Domine, F., Barret, M., Anastasio, C., Beine, H. J., Bottenheim, J., Grannas, A. M., Houdier, S., Netcheva, S., Rowland, G., Staebler, R., and Steffen, A.: Frost flowers growing in the Arctic ocean-atmosphere-sea ice-snow interface. Part 1: Chemical composition., J. Geophys. Res., 117, D00R09, doi:10.1029/2011JD016469, 2012.

Dubowski, Y. and Hoffmann, M. R.: Photochemical transformations in ice: Implications for the fate of chemical species, Geophys. 
Res. Lett., 27, 3321-3324, doi:10.1029/2000GL011701, 2000.

Ervens, B. and Volkamer, R.: Glyoxal processing by aerosol multiphase chemistry: towards a kinetic modeling framework of secondary organic aerosol formation in aqueous particles, Atmos. Chem. Phys., 10, 8219-8244, doi:10.5194/acp-10-8219-2010, 2010.

Felip, M., Sattler, B., Psenner, R., and Catalan, J.: Highly-Active Microbial Communities in the Ice and Snow Cover of HighMountain Lakes, Appl. Environ. Appl. Environ. Microbiol., 61, 2394-2401, 1995.

Finlay, J., Neff, J., Zimov, S., Davydova, A., and Davydov, S.: Snowmelt dominance of dissolved organic carbon in high-latitude watersheds: Implications for characterization and flux of river DOC, Geophys. Res. Lett., 33, L10401, doi:10.1029/2006GL025754, 2006.

Fisher, F. N., King, M. D., and Lee-Taylor, J.: Extinction of UVvisible radiation in wet midlatitude (maritime) snow: Implications for increased $\mathrm{NO}_{\mathrm{x}}$ emission, J. Geophys. Res., 110, D21301, doi:10.1029/2005JD005963, 2005.

Flanner, M. G., Zender, C. S., Randerson, J. T., and Rasch, P. J.: Present-day climate forcing and response from black carbon in snow, J. Geophys. Res.-Atmos., 112, D11202, doi:10.1029/2006JD008003, 2007.

Flanner, M. G., Liu, X., Zhou, C., Penner, J. E., and Jiao, C.: Enhanced solar energy absorption by internally-mixed black carbon in snow grains, Atmos. Chem. Phys., 12, 4699-4721, doi:10.5194/acp-12-4699-2012, 2012.

France, J. L., King, M. D., Frey, M. M., Erbland, J., Picard, G., Preunkert, S., MacArthur, A., and Savarino, J.: Snow optical properties at Dome C (Concordia), Antarctica; implications for snow emissions and snow chemistry of reactive nitrogen, Atmos. Chem. Phys., 11, 9787-9801, doi:10.5194/acp-11-97872011, 2011.

France, J. L., Reay, H. J., King, M. D., Voisin, D., Jacobi, H. W., Domine, F., Beine, H. J., Anastasio, C., and Lee-Taylor, J.: Hydroxyl radical and NOx production rates, black carbon concentrations, and light-absorbing impurities impurities in snow from field measurements, J. Geophys. Res., 117, D00R12, doi:10.1029/2011JD016639, 2012.

Fries, E., Sieg, K., Puttmann, W., Jaeschke, W., Winterhalter, R., Williams, J., and Moortgat, G. K.: Benzene, alkylated benzenes, chlorinated hydrocarbons and monoterpenes in snow/ice at Jungfraujoch (46.6 degrees N, 8.0 degrees E) during CLACE 4 and 5, Sci. Total Environ., 391, 269-277, 2008.

Fries, E., Starokozhev, E., Haunold, W., Jaeschke, W., Mitra, S. K., Borrmann, S., and Schmidt, M. U.: Laboratory studies on the uptake of aromatic hydrocarbons by ice crystals during vapor depositional crystal growth, Atmos. Environ., 41, 6156-6166, 2007.

Gabrieli, J., Vallelonga, P., Cozzi, G., Gabrielli, P., Gambaro, A., Sigl, M., Decet, F., Schwikowski, M., Gaeggeler, H., Boutron, C., Cescon, P., and Barbante, C.: Post 17th-Century Changes of European PAH Emissions Recorded in High-Altitude Alpine Snow and Ice, Environ. Sci. Technol., 44, 3260-3266, 2010.

Gao, S. S. and Abbatt, J. P. D.: Kinetics and mechanism of $\mathrm{OH}$ oxidation of small organic dicarboxylic acids in ice: Comparison to behavior in aqueous solution, J. Phys. Chem. A, 115, 99779986, 2011.

Gayley, R. I. and Ram, M.: Atmospheric dust in polar ice and the background aerosol, J. Geophys. Res., 90, 12921-12925,
doi:10.1029/JD090iD07p12921, 1985.

Gertner, B. J. and Hynes, J. T.: Model molecular dynamics simulation of hydrochloric acid ionization at the surface of stratospheric ice, Faraday Discuss., 110, 301-322, 1998.

Girardet, C. and Toubin, C.: Molecular atmospheric pollutant adsorption on ice: a theoretical survey, Surf. Sci. Rep., 44, 159-238, 2001.

Graber, E. R. and Rudich, Y.: Atmospheric HULIS: How humic-like are they? A comprehensive and critical review, Atmos. Chem. Phys., 6, 729-753, doi:10.5194/acp-6-729-2006, 2006.

Grannas, A. M., Hockaday, W. C., Hatcher, P. G., Thompson, L. G., and Mosley-Thompson, E.: New revelations on the nature of organic matter in ice cores, J. Geophys. Res., 111, D04304, doi:10.1029/2005JD006251, 2006.

Grannas, A. M., Bausch, A. R., and Mahanna, K. M.: Enhanced aqueous photochemical reaction rates after freezing, J. Phys. Chem. A, 111, 11043-11049, 2007a.

Grannas, A. M., Jones, A. E., Dibb, J., Ammann, M., Anastasio, C., Beine, H. J., Bergin, M., Bottenheim, J., Boxe, C. S., Carver, G., Chen, G., Crawford, J. H., Dominé, F., Frey, M. M., Guzmán, M. I., Heard, D. E., Helmig, D., Hoffmann, M. R., Honrath, R. E., Huey, L. G., Hutterli, M., Jacobi, H. W., Klán, P., Lefer, B., McConnell, J., Plane, J., Sander, R., Savarino, J., Shepson, P. B., Simpson, W. R., Sodeau, J. R., von Glasow, R., Weller, R., Wolff, E. W., and Zhu, T.: An overview of snow photochemistry: evidence, mechanisms and impacts, Atmos. Chem. Phys., 7, 43294373, doi:10.5194/acp-7-4329-2007, 2007b.

Grannas, A. M., Bogdal, C., Hageman, K. J., Halsall, C., Harner, T., Hung, H., Kallenborn, R., Klán, P., Klánová, J., Macdonald, R. W., Meyer, T., and Wania, F.: The role of the global cryosphere in the fate of organic contaminants, Atmos. Chem. Phys. Discuss., 12, 16923-17000, doi:10.5194/acpd-12-16923-2012, 2012.

Guzman, M. I., Photochemistry of pyruvic acid in water and ice, California Institute of Technology, CA, USA, Ph.D. Thesis, 2007.

Guzman, M. I., Colussi, A. J., and Hoffmann, M. R.: Photogeneration of distant radical pairs in aqueous pyruvic acid glasses, J. Phys. Chem. A, 110, 931-935, 2006a.

Guzman, M. I., Colussi, A. J., and Hoffmann, M. R.: Photoinduced oligomerization of aqueous pyruvic acid, J. Phys. Chem. A, 110, 3619-3626, 2006b.

Guzman, M. I., Hildebrandt, L., Colussi, A. J., and Hoffmann, M. R.: Cooperative Hydration of Pyruvic Acid in Ice, J. Am. Chem. Soc., 128, 10621-10624, 2006c.

Guzman, M. I., Hoffmann, M. R., and Colussi, A. J.: Photolysis of pyruvic acid in ice: Possible relevance to $\mathrm{CO}$ and $\mathrm{CO} 2$ ice core record anomalies, J. Geophys. Res.-Atmos., 112, D10123, doi:10.1029/2006JD007886, 2007.

Haan, D. and Raynaud, D.: Ice core record of $\mathrm{CO}$ variations during the last two millenia: Atmospheric implications and chemical interactions within the Greenland ice, Tellus B, 50, 253-262, 1998.

Hageman, K. J., Hafner, W. D., Campbell, D. H., Jaffe, D. A., Landers, D. H., and Simonich, S. L.: Variability in pesticide deposition and source contributions to snowpack in Western U.S. national park, Environ. Sci. Technol., 44, 4452-4458, 2010.

Hagler, G. S. W., Bergin, M. H., Smith, E. A., and Dibb, J. E.: A summer time series of particulate carbon in the air and snow at Summit, Greenland, J. Geophys. Res.-Atmos., 112, D21309, doi:10.1029/2007jd008993, 2007. 
Halde, R.: Concentration of impurities by progressive freezing, Water Res., 14, 575-580, 1980.

Hallquist, M., Wenger, J. C., Baltensperger, U., Rudich, Y., Simpson, D., Claeys, M., Dommen, J., Donahue, N. M., George, C., Goldstein, A. H., Hamilton, J. F., Herrmann, H., Hoffmann, T., Iinuma, Y., Jang, M., Jenkin, M. E., Jimenez, J. L., Kiendler-Scharr, A., Maenhaut, W., McFiggans, G., Mentel, Th. F., Monod, A., Prévôt, A. S. H., Seinfeld, J. H., Surratt, J. D., Szmigielski, R., and Wildt, J.: The formation, properties and impact of secondary organic aerosol: current and emerging issues, Atmos. Chem. Phys., 9, 5155-5236, doi:10.5194/acp-9-51552009, 2009.

Haynes, D. R., Tro, N. J., and George, S. M.: Condensation and Evaporation of of $\mathrm{H} 2 \mathrm{O}$ on Ice Surfaces, J. Phys. Chem., 96, 8502-8509, 1992.

Heger, D., Jirkovsky, J., and Klan, P.: Aggregation of methylene blue in frozen aqueous solutions studied by absorption spectroscopy, J. Phys. Chem. A, 109, 6702-6709, 2005.

Heger, D. and Klan, P.: Interactions of organic molecules at grain boundaries in ice: A solvatochromic analysis, J. Photochem. Photobiol. A, 187, 275-284, 2007.

Heger, D., Klanova, J., and Klan, P.: Enhanced protonation of cresol red in acidic aqueous solutions caused by freezing, J. Phys. Chem. B, 110, 1277-1287, 2006.

Heger, D., Nachtigallova, D., Surman, F., Krausko, J., Magyarova, B., Brumovsky, M., Rubes, M., Gladich, I., and Klan, P.: Selforganization of 1-methylnaphthalene on the surface of artificial snow grains: A combined experimental-computational approach, J. Phys. Chem. A, 115, 11412-11422, 2011.

Hegg, D. A., Warren, S. G., Grenfell, T. C., Doherty, S. J., and Clarke, A. D.: Sources of light-absorbing aerosol in arctic snow and their seasonal variation, Atmos. Chem. Phys., 10, 1092310938, doi:10.5194/acp-10-10923-2010, 2010.

Hegg, D. A., Warren, S. G., Grenfell, T. C., Doherty, S. J., Larson, T. V., and Clarke, A. D.: Source Attribution of Black Carbon in Arctic Snow, Environ. Sci. Technol., 43, 4016-4021, 2009.

Helmig, D., Apel, E., Blake, D., Ganzeveld, L., Lefer, B. L., Meinardi, S., and Swanson, A. L.: Release and uptake of volatile inorganic and organic gases through the snowpack at Niwot Ridge, Colorado, Biogeochemistry, 95, 167-183, 2009.

Herbert, B. M. J., Halsall, C. J., Jones, K. C., and Kallenborn, R.: Chemical interactions with snow: Understanding the behavior and fate of semi-volatile organic compounds in snow, Ecotoxicol. Environ. Safety 63, 3-16. 2006a.

Herbert, B. M. J., Halsall, C. J., Jones, K. C., and Kallenborn, R.: Field investigation into the diffusion of semi-volatile organic compounds into fresh and aged snow, Atmos. Environ. 40, 13851393. 2006b.

Hickman, Z. A. and Reid, B. J.: Increased microbial catabolic activity in diesel contaminated soil following addition of earthworms (Dendrobaena veneta) and compost, Soil Biol. Biochem., 40, 2970-2976, 2008.

Holmes, R. M., McClelland, J. W., Raymond, P. A., Frazer, B. B., Peterson, B. J., and Steiglitz, M.: Lability of DOC transported by Alaskan rivers to the Arctic Ocean, Geophys. Res. Lett., 35, L03402, doi:10.1029/2007GL032837, 2008.

Hood, E., Fellman, J., Spencer, R. G. M., Hernes, P. J., Edwards, R., D'Amore, D., and Scott, D.: Glaciers as a source of ancient and labile organic matter to the marine environment, Nature, 462,
1044-1047, 2009.

Houdier, S., Perrier, S., Domine, F., Cabanes, A., Legagneux, L., Grannas, A. M., Guimbaud, C., Shepson, P. B., Boudries, H., and Bottenheim, J. W.: Acetaldehyde and acetone in the Arctic snowpack during the ALERT2000 campaign. Snowpack composition, incorporation processes and atmospheric impact, Atmos. Environ., 36, 2609-2618, 2002.

Huthwelker, T., Ammann, M., and Peter, T.: The uptake of acidic gases on ice, ice, Chem. Rev., 106, 1375-1444, 2006.

Hutterli, M. A., McConnell, J. R., Bales, R. C., and Stewart, R. W.: Sensitivity of hydrogen peroxide $\left(\mathrm{H}_{2} \mathrm{O}_{2}\right)$ and formaldehyde (HCHO) preservation in snow to changing environmental conditions: Implications for ice core records, J. Geophys. Res.-Atmos., 108, 4023, doi:10.1029/2002JD002528, 2003.

Hutterli, M. A., Rothlisberger, R., and Bales, R. C.: Atmosphereto-snow-to-firn transfer studies of $\mathrm{HCHO}$ at Summit, Greenland, Geophys. Res. Lett., 26, 1691-1694, 1999.

Jedlovszky, P., Hantal, G., Neurohr, K., Picaud, S., Hoang, P. N. M., von Hessberg, P., and Crowley, J. N.: Adsorption isotherm of formic acid on the surface of ice, as seen from experiments and grand canonical Monte Carlo simulation, J. Phys. Chem. C, 112, 8976-8987, 2008.

Johnson, B. J., Betterton, E. A., and Craig, D.: Henry's law coefficients of formic and acetic acids, J. Atmos. Chem., 24, 113-119, 1996.

Journet, E., Le Calve, S., and Mirabel, P.: Adsorption study of acetone on acid-doped ice surfaces between 203 and 233 K, J. Phys. Chem. B, 109, 14112-14117, 2005.

Kahan, T. F. and Donaldson, D. J.: Benzene Photolysis on Ice: Implications for the Fate of Organic Contaminants in the Winter, Environ. Sci. Technol., 44, 3819-3824, 2010.

Kahan, T. F. and Donaldson, D. J.: Heterogeneous ozonation kinetics of phenanthrene at the air-ice interface, Environ. Res. Lett., 3, 2008.

Kahan, T. F. and Donaldson, D. J.: Photolysis of polycyclic aromatic hydrocarbons on water and ice surfaces, J. Phys. Chem. A, 111, 1277-1285, 2007.

Kahan, T. F., Kwamena, N. O. A., and Donaldson, D. J.: Different photolysis kinetics at the surface of frozen freshwater vs. frozen salt solutions, Atmos. Chem. Phys., 10, 10917-10922, doi:10.5194/acp-10-10917-2010, 2010a.

Kahan, T. F., Zhao, R., and Donaldson, D. J.: Hydroxyl radical reactivity at the air-ice interface, Atmos. Chem. Phys., 10, 843-854, doi:10.5194/acp-10-843-2010, 2010b.

Kahan, T. F., Zhao, R., Jumaa, K. B., and Donaldson, D. J.: Anthracene Photolysis in Aqueous Solution and Ice: Photon Flux Dependence and Comparison Comparison of Kinetics in Bulk Ice and at the Air-Ice Interface, Environ. Sci. Technol., 44, 13021306, 2010c.

Kaleschke, L., Richter, A., Burrows, J., Afe, O., Heygster, G., Notholt, J., Rankin, A. M., Roscoe, H. K., Hollwedel, J., Wagner, T., and Jacobi, H. W.: Frost flowers on sea ice as a source of sea salt and their influence on tropospheric halogen chemistry, Geophys. Res. Lett., 31, L16114, doi:10.1029/2004GL020655, 2004.

Kang, J. H., Choi, S. D., Park, H., Baek, S. Y., Hong, S., and Chang, Y. S.: Atmospheric deposition of persistent organic pollutants to the East Rongbuk Glacier in the Himalayas, Sci. Total Environ., 408, 57-63, 2009. 
Kawamura, K., Kasukabe, H., Yasui, O., and Barrie, L. A.: Production of dicarboxylic acids in the Arctic atmosphere at polar sunrise, Geophys. Res. Lett., 22 (10), 1253-1256, 1995.

Kawamura, K., Yokoyama, K., Fujii, Y., and Watanabe, O.: A Greenland ice core record of low molecular weight dicarboxylic acids, ketocarboxylic acids, and alpha-dicarbonyls: A trend from Little Ice Age to the present (1540 to 1989 (1540 to 1989 A.D.), J. Geophys. Res., 106, 1331-1345, 2001.

Kemball, C. and Rideal, E. K.: The adsorption of vapours on mercury. 1. Non-polar substances, Proc. Roy. Soc. A, 187, 53-73, 1946.

Kerbrat, M., Huthwelker, T., Bartels-Rausch, T., Gaggeler, H. W., and Ammann, Ammann, M.: Co-adsorption of acetic acid and nitrous acid on ice, Phys. Chem. Chem. Phys., 12, 7194-7202, 2010.

Kerbrat, M., Le Calve, S., and Mirabel, P.: Uptake measurements of ethanol on ice surfaces and on supercooled aqueous solutions doped with nitric acid between 213 and 243 K, J. Phys. Chem. A, 111, 925-931, 2007.

Kim, K. and Choi, W.: Enhanced redox conversion of chromate and arsenite in ice, Environ. Sci. Technol., 45, 2202-2208, 2011.

Kim, K., Choi, W., Hoffmann, M. R., Yoon, H. I., and Park, B. K.: Photoreductive dissolution of iron oxides trapped in ice and its environmental implications, Environ. Sci. Technol., 44, 41424148, 2010.

Kippenberger, M., Winterhalter, R., and Moortgat, G. K.: Determination of higher carboxylic acids in snow samples using solidphase extraction and LC/MS-TOF, Anal. Bioanal. Chem., 392, 1459-1470, 2008.

Klan, P., Ansorgova, A., Del Favero, D., and Holoubek, I.: Photochemistry of chlorobenzene in ice, Tetrahedron Lett., 41, 77857789, 2000.

Klan, P., Del Favero, D., Ansorgova, A., Klanova, J., and Holoubek, I.: Photodegradation of halobenzenes in water ice, Environ. Sci. Pollut. Res., 9, 195-200, 2001.

Klan, P. and Holoubek, I.: Ice (Photo)chemistry, Ice as a Medium for Long-term (Photo)chemical Transformations - Environmental Implications, Chemosphere, 46, 1201-1210, 2002.

Klan, P. and Wirz, J.: Photochemistry of Organic Compounds: From Concepts to Practice, Wiley, Chichester, UK, 183-223, 2009.

Klanova, J., Klan, P., Heger, D., and Holoubek, I.: Comparison of the effects of UV, H2O2/UV, and gamma-irradiation processes on frozen and liquid water solutions of monochlorophenols, Photochem. Photobiol. Sci., 2, 1023-1031, 2003a.

Klanova, J., Klan, P., Nosek, J., and Holoubek, I.: Environmental ice photochemistry: Monochlorophenols, Environ. Sci. Technol., 37, 1568-1574, 2003b.

Kos, G. and Ariya, P. A.: Volatile organic compounds in snow in the Quebec-Windsor Corridor, J. Geophys. Res.-Atmos., 115(D01302), doi:10.1029/2009JD012391, 2010.

Krepelova, A., Newberg, J. T., Huthwelker, T., Bluhm, H., and Ammann, M.: The nature of nitrate at the ice surface studied by XPS and NEXAFS, Phys. Chem. Chem. Phys., 12, 8870-8880, 2010.

Kuo, M. H., Moussa, S. G., and McNeill, V. F.: Modeling interfacial liquid layers on environmental ices, Atmos. Chem. Phys., 11, 9971-9982, doi:10.5194/acp-11-9971-2011, 2011.

Kurkova, R., Ray, D., Nachtigallova, D., and Klan, P.: Chemistry of Small Organic Molecules on Snow Grains: The Applicability of Artificial Snow for Environmental Studies, Environ. Sci.
Technol., 45, 3430-3436, 2011.

Lacorte, S., Quintana, J., Tauler, R., Ventura, F., Tovar-Sanchez, A., and Duarte, C. M.: Ultra-trace determination of Persistent Organic Pollutants in Arctic ice using stir bar sorptive extraction and gas chromatography coupled to mass spectrometry, J. Chromatography A, 1216, 8581-8589, 2009.

Le Borgne, S., Paniagua, D., and Vazquez-Duhalt, R.: Biodegradation of organic pollutants by halophilic bacteria and archaea, J. Molec. Microbiol. Biotech., 15, 74-92, 2008.

Lee, E., Park, H., and Cho, K.-S.: Characterization of methane, benzene, and toluene-oxidizing consortia enriched from landfill and riparian wetland soils, J. Haz. Mat., 184, 313-320, 2010.

Lee-Taylor, J. and Madronich, S.: Calculation of actinic fluxes with a coupled atmosphere-snow radiative transfer model, J. Geophys. Res., 107 (4796), doi:10.1029/2002JD002084, 2002.

Legrand, M. and Deangelis, M.: Origins and variations of light carboxylic acids in polar precipication, J. Geophys. Res.-Atmos., 100, 1445-1462, 1995.

Legrand, M., Preunkert, S., Schock, M., Cerqueira, M., KasperGiebl, A., Afonso, J., Pio, C., Gelencser, A., and DombrowskiEtchevers, L.: Major 20th century changes of carbonaceous aerosol components (EC, WinOC, DOC, HULIS, carboxylic acids, and cellulose) derived from Alpine ice cores, J. Geophys. Res.-Atmos., 112, D23S11, doi:10.1029/2006JD008080, 2007.

Lei, Y. D. and Wania, F.: Is rain or snow a more efficient scavenger of organic chemicals?, Atmos. Environ., 38, 3557-3571, 2004.

Lewis, G. N., Goldschmid, O., Magel, T. T., and Bigeleisen, J.: Dimeric and other forms of methylene blue absorption and fluorescence of the pure monomer, J. Am. Chem. Soc., 65, 11501154, 1943.

Li, Q., Wang, N., Wu, X., Pu, J., He, J., and Zhang, C.: Sources and distribution of polycyclic aromatic hydrocarbons of different glaciers over the Tibetan Plateau, Sci. China-Earth Sci., 54, 1189-1198, 2011.

Liyana-Arachchi, T. P., Valsaraj, K. T., and Hung, F. R.: Molecular simulation study of the adsorption of naphthalene and ozone on atmospheric air/ice interfaces, J. Phys. Chem. A, 115, 92269236, 2011.

Lohmann, U. and Leck, C.: Importance of submicron surface-active organic aerosols for pristine Arctic clouds, Tellus B, 57, 261268, 2005.

Mabilia, R., Di Palo, V., Cassardo, C., Ciuchini, C., Pasini, A., and Possanzini, M.: Measurements of lower carbonyls and hydrocarbons at Ny-Alesund, svalbard, Ann. Chim., 97, 1027-1037, 2007.

Matykiewiczova, N., Klanova, J., and Klan, P.: Photochemical degradation of PCBs in snow, Environ. Sci. Technol., 41, 83088314, 2007a.

Matykiewiczova, N., Kurkova, R., Klanova, J., and Klan, P.: Photochemically induced nitration and hydroxylation of organic aromatic compounds in the presence of nitrate or nitrite in ice, J. Photochem. Photobiol. A, 187, 24-32, 2007b.

McConnell, J. R., Edwards, R., Kok, G. L., Flanner, M. G., Zender, C. S., Saltzman, E. S., Banta, J. R., Pasteris, D. R., Carter, M. M., and Kahl, J. D. W.: 20th-Century Industrial Black Carbon Emissions Altered Arctic Climate Forcing, Science, 317, 13811384, 2007.

McNeill, V. F., Geiger, F. M., Loerting, T., Trout, B. L., and Molina, M. J.: The Interaction of Hydrogen Chloride with Ice Surfaces: 
The Effects of Grain Size, Surface

Roughness, and Surface Disorder, J. Phys. Chem. A, Roughness, and Surface Disorder, J. Phys. Chem. A, 111, 6274-6284, 2007.

McNeill, V. F., Loerting, T., Geiger, F. M., Trout, B. L., and Molina, M. J.: Hydrogen chloride-induced surface disordering on ice, Proc. Natl. Acad. Sci. USA, 103, 9422-9427, 2006.

Meyer, T., Duan, L. Y., Muradi, I., and Wania, F.: Organic contaminant release from melting snow. 1. Influence of chemical partitioning, Environ. Sci. Technol., 43, 657-662, 2011a.

Meyer, T., Lei, Y. D., and Wania, F.: Transport of polycyclic aromatic hydrocarbons and pesticides during snowmelt within an urban watershed, Water Res., 45, 1147-1156, 2011 b.

Meyer, T. and Wania, F.: Organic contaminant amplification during snowmelt, Water Res., 42, 1847-1865, 2008.

Meyer, T. and Wania, F.: Modeling the elution of organic chemicals from a melting homogeneous snow pack, Water Res., 45, 36273637, 2011.

Mmereki, B. T., Hicks, J. M., and Donaldson, D. J.: Adsorption of atmospheric gases at the air-water interface. 3: methylamines $\mathrm{J}$. Phys. Chem A, 104, 10789-10793, 2000.

Moore, R. M., Geen, C. E., and Tait, V. K.: Determination of Henry Law Constants for A Suite of Naturally-Occurring Halogenated Methanes in Seawater, Chemosphere, 30, 1183-1191, 1995.

Mortazavi, R., Hayes, C. T., and Ariya, P. A.: Ice nucleation activity of bacteria isolated from snow compared with organic and inorganic substrates, Environ. Chem., 5, 373-381, 2008.

Mortazavi, R., Kos, G., Kanthaswamy, V., and Ariya, P. A.: Biomaterials in Arctic, submitted, 2012.

Murphy, D. M. and Koop, T.: Review of the vapour pressures of ice and supercooled water for atmospheric applications, Q. J. Roy. Meteor. Soc., 131, 1539-1565, 2005.

Muyzer, G. and van der Kraan, G. M.: Bacteria from hydrocarbon seep areas growing on short-chain alkanes, Trends Microbiol., 16, 138-141, 2008.

Norman, L., Thomas, D. N., Stedmon, C. A., Granskog, M. A., Papadimitriou, S., Krapp, R. H., Meiners, K. M., Lannuzel, D., van der Merwe, P., and Dieckmann, G. S.: The characteristics of dissolved organic matter (DOM) and chromophoric dissolved organic matter (CDOM) in Antarctic sea ice, Deep-Sea Res. II, 58, 1075-1091, 2011.

Noziere, B., Dziedzic, P., and Cordova, A.: Formation of secondary light-absorbing "fulvic-like" oligomers: A common process in aqueous and ionic atmospheric particles?, Geophys. Res. Lett., 34, L21812, doi:10.1029/2007GL031300, 2007.

Partay, L., Jedlovszky, P., Hoang, P. N. M., Picaud, S., and Mezei, M.: Free-Energy Profile of Small Solute Molecules at teh Free Surfaces of Water and Ice, as Determined by Cavity Insertion Widom Calculations, J. Phys. Chem. C, 111, 9407-9416, 2007.

Parungo, F. P. and Pueschel, R. F.: Ice Nucleation: Elemental Identification of Particles in Snow Crystals, Science, 180, 1057-1058, 1973.

Pautler, B. G., Simpson, A. J., Simpson, M. J., Tseng, L.-H., Spraul, M., Dubnick, A., Sharp, M. J., and Fitzsimmons, S. J.: Detection and Structural Identification of Dissolved Organic Matter in Antarctic Glacial Ice at Natural Abundance by SPR-W5WATERGATE (1)H NMR Spectroscopy, Environ. Sci. Technol., 45, 4710-4717, 2011.

Perovich, D. K.: The changing Arctic sea ice cover, Oceanography, 24, 162-173, 2011.
Perovich, D. K. and Richter-Menge, J. A.: Surface Characteristics of Lead Ice, J. Geophys. Res.-Oceans, 99, 16341-16350, 1994.

Perrier, S., Houdier, S., Domine, F., Cabanes, A., Legagneux, L., Sumner, A. L., and Shepson, P. B.: Formaldehyde in Arctic snow. Incorporation into ice particles and evolution in the snowpack, Atmos. Environ., 36, 2695-2705, 2002.

Petitjean, M., Mirabel, P., and Le Calve, S.: Uptake Measurements of Acetaldehyde on Solid Ice Surfaces and on Solid/Liquid Supercooled Mixtures Doped with HNO3 in the Temperature Range 203-253 K, J. Phys. Chem. A, 113, 5091-5098, 2009.

Pincock, R. E.: Reactions in frozen systems, Acc. Chem. Res., 2, 97-103, 1969.

Pouvesle, N., Kippenberger, M., Schuster, G., and Crowley, J. N.: The interaction of $\mathrm{H}(1) \mathrm{O}(1)$ with ice surfaces between 203 and 233 K, Phys. Chem. Chem. Phys., 12, 15544-15550, 2010.

Preunkert, S., Wagenbach, D., and Legrand, M.: A seasonally resolved alpine ice core record of nitrate: Comparison with anthropogenic inventories and estimation of preindustrial emissions of NO in Europe, J. Geophys. Res.-Atmos., 108, 4681, doi:10.1029/2003JD003475, 2003.

Ram, K. and Anastasio, C.: Photochemistry of phenanthrene, pyrene, and fluoranthene in ice and snow, Atmos. Environ., 43, 2252-2259, 2009.

Ramamurthy, V.: Organic photochemistry in organized media, Tetrahedron , 42, 5753-5839, 1986.

Ramseier, R. O.: Self-diffusion of tritium in natural and synthetic ice monocrystals, J. Appl. Phys., 38, 2553-2556, 1967.

Ray, D., Kurkova, R., Hovorkova, I., and Klan, P.: Determination of the specific surface area of snow using ozonation of 1,1-Diphenylethylene, Environ. Sci. Technol., 45, 10061-10067, 2011.

Riedel, A., Michel, C., Gosselin, M., and LeBlanc, B.: Winterspring dynamics dynamics in sea-ice carbon cycling in the coastal Arctic Ocean, J. Marine Syst., 74, 918-932, 2008.

Rincon, A. G., Guzman, M. I., Hoffmann, M. R., and Colussi, A. J.: Optical Absorptivity versus Molecular Composition of Model Organic Aerosol Matter, J. Phys. Chem. A, 113, 10512-10520, 2009.

Rincon, A. G., Guzman, M. I., Hoffmann, M. R., and Colussi, A. J.: Thermochromism of Model Organic Aerosol Matter, J. Phys. Chem. Lett., 1, 368-373, 2010.

Roberts, J. L., vas Ommen, T. D., Curran, M. A. J., and Vance, T. R.: Methanesulphonic acid loss during ice-core storage: Recommendations based on a new diffusion coefficient, J. Glaciol., 55, 784-788, 2009.

Robinson, C., Boxe, C. S., Guzman, M. I., Colussi, A. J., and Hoffmann, M. R.: Acidity of Frozen Electrolyte Solutions, J. Phys. Chem. B, 110, 7613-7616, 2006.

Roth, C. M., Goss, K. U., and Schwarzenbach, R. P.: Sorption of diverse organic vapors to snow, Environ. Sci. Technol., 38, 40784084. 2004.

Rowland, G. A., Bausch, A. R., and Grannas, A. M.: Photochemical processing of aldrin and dieldrin in frozen aqueous solutions under arctic field conditions, Environ. Pollut., 159, 1076-1084, 2011.

Ruzicka, R., Barakova, L., and Klan, P.: Photodecarbonylation of dibenzyl ketones and trapping of radical intermediates by copper(II) chloride in frozen aqueous solutions, J. Phys. Chem. B, 109, 9346-9353, 2005. 
Salmon, R. A., Bauguitte, S. J.-B., Bloss, W., Hutterli, M. A., Jones, A. E., Read, K., and Wolff, E. W.: Measurement and interpretation of gas phase formaldehyde concentrations obtained during the CHABLIS campaign in coastal Antarctica, Atmos. Chem. Phys., 8, 4085-4093, doi:10.5194/acp-8-4085-2008, 2008.

Sareen, N., Schwier, A. N., Shapiro, E. L., Mitroo, D., and McNeill, V. F.: Secondary organic material formed by methylglyoxal in aqueous aerosol mimics, Atmos. Chem. Phys., 10, 997-1016, doi:10.5194/acp-10-997-2010, 2010.

Savarino, J. and Legrand, M.: High northern latitude forest fires and vegetation emissions over the last millenium inferred from the chemistry of a central Greenland ice core, J. Geophys. Res., 103, 8267-8279, 1998.

Saxena, P. and Hildemann, L. M.: Water-soluble organics in atmospheric particles: A critical review of the literature and application of thermodynamics to identify candidate compounds, J. Atmos. Chem., 24, 57-109, 1996.

Scatena, L. F., Brown, M. G., and Richmond, G. L.: Water at hydrophobic surface: Weak hydrogen bonding and strong orientation effects, Science, 292, 908-912, 2001.

Schwier, A. N., Sareen, N., Mitroo, D. M., Shapiro, E. L., and McNeill, V. F.: Glyoxal-Methylglyoxal Cross-Reactions in Secondary Organic Aerosol Formation, Environ. Sci. Technol., 44, 6174-6182, 2010.

Seinfeld, J. H. and Pankow, J. F.: Organic atmospheric particulate material, Ann. Rev. Phys. Chem., 54, 121-140, 2003.

Shapiro, E. L., Szprengiel, J., Sareen, N., Jen, C. N., Giordano, M. R., and McNeill, V. F.: Light-absorbing secondary organic material formed by glyoxal in aqueous aerosol mimics, Atmos. Chem. Phys., 9, 2289-2300, doi:10.5194/acp-9-2289-2009, 2009.

Shaw, P. M., Russell, L. M., Jefferson, A., and Quinn, P. K.: Arctic organic aerosol measurements show particles from mixed combustion in spring haze and from frost flowers in winter, Geophys. Res. Lett., 37(L10803), doi:10.1029/2010GL042831, 2010.

Shepson, P. B., Ariya, P. A., Deal, C. J., Donaldson, D. J., Douglas, T. A., Loose, B., Maksym, T., Matrai, P. A., Russell, L. M., Saenz, B., Stefels, J., and Steiner, N.: Changing Polar Environments: Interdisciplinary Challenges, EOS Trans., American Geophysical Union, 93, 117-124. 2012.

Sieg, K., Fries, E., and Püttmann, W.: Analysis of benzene, toluene, ethylbenzene, xylenes and n-aldehydes in melted snow water via solid-phase dynamic extraction combined with gas chromatography/mass spectrometry, J. Chromatog. A, 1178, 178-186, 2008.

Smith, M. and Pounder, E. R.: Impurity concentration profiles in ice by an anthrone method, Can. J. Phys., 38, 354-368, 1960.

Sokolov, O. and Abbatt, J. P. D.: Adsorption to ice of n-alcohols (ethanol to 1-hexanol), acetic acid, and hexanal, J. Phys. Chem. A, 106, 775-782, 2002.

Starokozhev, E., Sieg, K., Fries, E., and Puttmann, W.: Investigation of partitioning mechanism for volatile organic compounds in a multiphase system, system, Chemosphere, 82, 1482-1488, 2011.

Starr, D. E., Pan, D., Newberg, J. T., Ammann, M., Wang, E. G., Michaelides, A., and Bluhm, H.: Acetone adsorption on ice investigated by X-ray spectroscopy and density functional theory, Phys. Chem. Chem. Phys., 13, 19988-19996, 2011.

Stubbins, A., Hood, E., Raymond, P. A., Aiken, G. R., Sleighter, R. L., Hernes, P. J., Butman, D., Hatcher, P. G., Striegl, R. G., Schuster, P., Abdulla, H. A. N., Vermilyea, A. W., Scott, D. T., and Spencer, R. G. M.: Anthropogenic aerosols as a source of ancient dissolved organic matter in glaciers, Nature Geosci., 5, 198-201, 2012.

Sumner, A. L., Shepson, P. B., Grannas, A. M., Bottenheim, J. W., Anlauf, K. G., Worthy, D., Schroeder, W. H., Steffen, A., Domine, F., Perrier, S., and Houdier, S.: Atmospheric chemistry of formaldehyde in the Arctic troposphere at Polar Sunrise, and the influence of the snowpack, Atmos. Environ., 36, 2553-2562, 2002.

Sumner, A. L. and Shepson, P. B.: Snowpack production of formaldehyde and its its effect on the Arctic troposphere, Nature, 398, 230-233, 1999.

Sun, J. M., Ariya, P. A., Leighton, H. G., and Yau, M. K.: Mystery of ice multiplication in warm-based precipitating shallow cumulus clouds, Geophys. Res. Lett., 37, L10802, doi:10.1029/2010GL042440, 2010.

Symington, A., Cox, R. A., and Fernandez, M. A.: Uptake of Organic Acids on Ice Surfaces: Evidence for Surface Modification and Hydrate Formation, Z. Phys. Chem., 224, 1219-1245, 2010.

Szyrmer, W. and Zawadzki, I.: Biogenic and anthropogenic sources of ice-forming nuclei: A review, B. Am. Meteor. Soc., 78, 209228, 1997.

Takenaka, N. and Bandow, H.: Chemical kinetics of reactions in the unfrozen solution of ice, J. Phys. Chem. A, 111, 8780-8786, 2007.

Takenaka, N., Tanaka, M., Okitsu, K., and Bandow, H.: Rise in the $\mathrm{pH}$ of an unfrozen solution in ice due to the presence of $\mathrm{NaCl}$ and promotion of decomposition of gallic acids owing to a change in the pH., J. Phys. Chem. A, 110, 10628-10632, 2006.

Thibert, E. and Domine, F.: Thermodynamics and Kinetics of the Solid Solution Solution of $\mathrm{HCl}$ in Ice, J. Phys. Chem. B, 101, 3554-3565, 1997.

Thibert, E. and Domine, F.: Thermodynamics and Kinetics of the Solid Solution Solution of $\mathrm{HNO}_{3}$ in Ice, J. Phys. Chem. B, 102, 4432-4439, 1998.

Thomas, D. N. and Dieckmann, G. S.: Ocean science - Antarctic Sea ice - a habitat for extremophites, Science, 295, 641-644, 2002.

Timmis, K. N. and Pieper, D. H.: Bacteria designed for bioremediation, Trends Biotechnol., 17, 201-204, 1999.

Tschumi, J. and Stauffer, B.: Reconstructing past atmospheric CO2 concentration based on ice-core analyses: Open questions due to in situ production of $\mathrm{CO}_{2}$ in the ice, J. Glaciol., 46, 45-53, 2000.

Ullerstam, M. and Abbatt, J. P. D.: Burial of gas-phase HNO3 by growing ice surfaces under tropospheric conditions, Phys. Chem. Chem. Phys., 7, 3596-3600, 2005.

Ulrich, T., Ammann, M., Leutwyler, S., and Bartels-Rausch, T.: The adsorption of peroxynitric acid on ice between $230 \mathrm{~K}$ and $253 \mathrm{~K}$, Atmos. Chem. Phys., 12, 1833-1845, doi:10.5194/acp-12-18332012, 2012.

Uritski, A. and Huppert, D.: Photoacid-base reaction in ice via a mobile L-defect., J. Phys. Chem. A, 112, 3066-3078, 2008.

Uritski, A., Presiado, I., Erez, Y., Gepshtein, R., and Huppert, D.: Classification of acids and acidities in I-h Ice II: Reversible photoacids as a probe for proton concentration., J. Phys. Chem. C, 113, 12901-12910, 2009a.

Uritski, A., Presiado, I., Erez, Y., Gepshtein, R., and Huppert, D.: Temperature dependence of proton diffusion in I-h ice, J. Phys. Chem. C, 113, 10285-10296, 2009b. 
Usenko, S., Smonich, S. L. M., Hageman, K. J., Schrlau, J. E., Geiser, L., Campbell, D. H., Appleby, P. G., and Landers, D. H.: Sources and Deposition of Polycyclic Aromatic Hydrocarbons to Western US National Parks, Environ. Sci. Technol., 44, 4512-4518, 2010.

Voisin, D., Jaffrezo, J.-L., Houdier, S., Barret, M., Cozic, J., King, M. D., France, J. L., Reay, H. J., Grannas, A. M., Kos, G., Ariya, P. A., Beine, H. J., and Domine, F.: Carbonaceous species and HUmic LIke Substances (HULIS) in Arctic snowpack during OASIS field campaign in Barrow, J. Geophys. Res., 117, D00R19, doi:10.1029/2011JD016612, 2012.

von Hessberg, P., Pouvesle, N., Winkler, A. K., Schuster, G., and Crowley, J. N.: Interaction of formic and acetic acid with ice surfaces between 187 and $227 \mathrm{~K}$. Investigation of single species- and competitive adsorption, Phys. Chem. Chem. Phys., 10, 23452355. 2008.

von Schneidemesser, E., Schauer, J. J., Shafer, M. M., Hagler, G. S. W., Bergin, M. H., and Steig, E. J.: A method for the analysis of ultra-trace levels of semi-volatile and non-volatile organic compounds in snow and application to a Greenland snow pit, Polar Sci., 2, 251-266, 2008.

Walker, J. D., Seesman, P. A., Herbert, T. L., and Colwell, R. R.: Petroleum Hydrocarbons - Degradation and Growth Potential of Deep-Sea Sediment Bacteria, Environ. Pollut., 10, 89-99, 1976.

Wania, F., Mackay, D., and Hoff, J. T.: The importance of snow scavenging of polychlorinated biphenyl and polycyclic aromatic hydrocarbon vapors, Environ. Sci. Technol., 33, 195-197, 1999.

Warren, S. G. and Wiscombe, W. J.: A Model for the Spectral Albedo of Snow. II: Snow Containing Atmospheric Aerosols, J. Atmos. Sci., 37, 2734-2745, 1980.

Weber, J., Kurkova, R., Klanova, J., Klan, P., and Halsall, C. J.: Photolytic degradation of methyl-parathion and fenitrothion in ice and water: Implications for cold environments, Environ. Pollut., 157, 3308-3313, 2009.

Wettlaufer, J. S.: Impurity Effects in the Premelting of Ice, Phys. Rev. Lett., 82, 2516-2519, 1999.

Williams, M. W., Helmig, D., and Blanken, P.: White on green: under-snow microbial processes and trace gas fluxes through snow, Niwot Ridge, Colorado Front Range, Biogeochemistry, 95, 1-12, 2009.
Winterhalter, R., Kippenberger, M., Williams, J., Fries, E., Sieg, K., and Moortgat, G. K.: Concentrations of higher dicarboxylic acids C5-C13 in fresh snow samples collected at the High Alpine Research Station Jungfraujoch during CLACE 5 and 6, Atmos. Chem. Phys., 9, 2097-2112, doi:10.5194/acp-9-2097-2009, 2009.

Workman, E. J. and Reynolds, S. E.: Electrical Phenomena Occurring During the Freezing of Dilute Aqueous Solutions and Their Possible Relationship to Thunderstorm Electricity, Phys. Rev., 78, 254-259, 1950.

Wren, S. N., Kahan, T. F., Jumaa, K. B., and Donaldson, D. J.: Spectroscopic studies of the heterogeneous reaction between $\mathrm{O}-3(\mathrm{~g})$ and halides at the surface of frozen salt solutions, J. Geophys. Res.-Atmos., 115, D16309, doi:10.1029/2010JD013929, 2010.

Wren, S.N. and Donaldson, D.J.: Laboratory Study of $\mathrm{pH}$ at the Air-Ice Interface, J. Phys. Chem. C, 116, 10171-10180, 2012.

Xu, Y., Simpson, A. J., Eyles, N., and Simpson, M. J.: Sources and molecular composition of cryoconite organic matter from the Athabasca Glacier, Canadian Canadian Rocky Mountains, Org. Geochem., 41, 177-186, 2010.

Yamamoto, S., Alcauskas, J. B., and Crozier, T. E.: Solubility of Methane in Distilled Water and Seawater, J. Chem. Eng. Data, 21, 78-80, 1976.

Yasunari, T. J., Bonasoni, P., Laj, P., Fujita, K., Vuillermoz, E., Marinoni, A., Cristofanelli, P., Duchi, R., Tartari, G., and Lau, K.-M.: Estimated impact of black carbon deposition during premonsoon season from Nepal Climate Observatory - Pyramid data and snow albedo changes over Himalayan glaciers, Atmos. Chem. Phys., 10, 6603-6615, doi:10.5194/acp-10-6603-2010, 2010.

Yaws, C. L.: Yaws' Handbook of Thermodynamic and Physical Properties of Chemical Compounds, Knovel, available at: http://www.knovel.com.ezproxy.cul.columbia.edu/web/ portal/browse/display?_EXT_KNOVEL_DISPLAY_bookid= $667 \&$ VerticalID $=0,2003$. 